\title{
Indol-2-yl ethanones as novel indoleamine 2,3-dioxygenase (ID0) inhibitors
}

\author{
Eduard Dolušićc ${ }^{\mathrm{a}}$, Pierre Larrieu ${ }^{\mathrm{b}}$, Sébastien Blanc ${ }^{\mathrm{c}}$, Frédéric Sapunaric ${ }^{\mathrm{d}}$, Bernadette Norberg ${ }^{\mathrm{a}}$, \\ Laurence Moineaux $^{\mathrm{a}}$, Delphine Colette ${ }^{\mathrm{c}}$, Vincent Stroobant ${ }^{\mathrm{b}}$, Luc Pilotte ${ }^{\mathrm{b}}$, Didier Colau ${ }^{\mathrm{b}}$, Thierry Ferain ${ }^{\mathrm{c}}$, \\ Graeme Fraser $^{c}$, Moreno Galeni ${ }^{\mathrm{d}}$, Jean-Marie Frère ${ }^{\mathrm{d}}$, Bernard Masereel ${ }^{\mathrm{a}}$, Benoît Van den Eynde ${ }^{\mathrm{b}}$, \\ Johan Wouters $^{\text {a }}$, Raphaël Frédérick ${ }^{\mathrm{a}, *}$ \\ a Drug design and Discovery Center, University of Namur, 61 Rue de Bruxelles, 5000 Namur, Belgium \\ ${ }^{\mathrm{b}}$ Ludwig Institute for Cancer Research, Université Catholique de Louvain, 74 Avenue Hippocrate, 1200 Brussels, Belgium \\ ${ }^{\mathrm{c}}$ Euroscreen SA, 47 Rue Adrienne Boland, 6041 Gosselies, Belgium \\ d Centre d'Ingénierie des Protéines, Université de Liège, Allée du 6 août, 4000 Liège, Belgium
}

\section{A R T I C L E I N F O}

Article history:

Received 1 October 2010

Revised 7 December 2010

Accepted 13 December 2010

Available online $\mathrm{xxxx}$

\section{Keywords:}

Indoleamine 2,3-dioxygenase

IDO

Anticancer

Immunotherapy

\begin{abstract}
A B S T R A C T
Indoleamine 2,3-dioxygenase (IDO) is a heme dioxygenase which has been shown to be involved in the pathological immune escape of diseases such as cancer. The synthesis and structure-activity relationships (SAR) of a novel series of IDO inhibitors based on the indol-2-yl ethanone scaffold is described. In vitro and in vivo biological activities have been evaluated, leading to compounds with $\mathrm{IC}_{50}$ values in the micromolar range in both tests. Introduction of small substituents in the 5- and 6-positions of the indole ring, indole $\mathrm{N}$-methylation and variations of the aromatic side chain are all well tolerated. An iron coordinating group on the linker is a prerequisite for biological activity, thus corroborating the virtual screening results.
\end{abstract}

(c) 2010 Elsevier Ltd. All rights reserved.

\section{Introduction}

Immunotherapy is a promising novel strategy for cancer treatment. It consists of therapeutic vaccination of cancer patients in order to stimulate their (natural) immune system against cancer cells. This approach, however, showed limited efficacy in vivo. Indeed, cancer cells are able to develop enzymatic mechanisms allowing tumors to resist or escape immune rejection. Among the enzymes involved, the indoleamine 2,3-dioxygenase (IDO; EC 1.13.11.52) represents a crucial actor. ${ }^{1,2}$

IDO is a $\sim 45 \mathrm{kDa}$ monomeric extrahepatic cytosolic heme dioxygenase which catalyzes the initial and rate-limiting step in the catabolism of the essential amino acid tryptophan (Trp) along the kynurenine pathway, the de novo biosynthetic route leading to nicotinamide adenine dinucleotide (NAD). ${ }^{3,4}$ IDO is a more promiscuous enzyme than the catalytically related hepatic enzyme tryptophan 2,3-dioxygenase (TDO; EC 1.13.11.11). Apart from both tryptophan enantiomers, IDO substrates are indoleamines such as serotonin, melatonin, and tryptamine. ${ }^{5}$ In order for IDO to be catalytically active, it is essential to maintain the heme iron ion in the ferrous $\left(\mathrm{Fe}^{2+}\right)$ state. As the enzyme is susceptible to autoxidation, a reductant is necessary for preserving the enzymatic activity. Cytochrome $b_{5}$ has been demonstrated to play this role in vivo.,

\footnotetext{
* Corresponding author. Tel.: +32 817242 90; fax: +32 81724238

E-mail address: Raphael.frederick@fundp.ac.be (R. Frédérick).
}

By depleting Trp locally, IDO blocks the proliferation of T lymphocytes, which are sensitive to Trp shortage. ${ }^{8}$ The downstream catabolites of the kynurenine pathway exacerbate this immunosuppressive effect ${ }^{1}$ and are also involved in other pathological conditions, particularly in the nervous system. ${ }^{9-11}$

Many human tumors constitutively express IDO. ${ }^{12}$ It has been shown that an increased level of IDO expression in tumor cells is correlated with poor prognosis for survival in cancer. ${ }^{13,14}$ This led to the hypothesis that IDO inhibition might enhance the efficacy of cancer treatments. Indeed, results from in vitro and in vivo studies have suggested an improvement of the efficacy of therapeutic vaccination or chemotherapy by concomitant administration of an IDO inhibitor thus highlighting IDO as an attractive target. ${ }^{12,13,15-17}$

Until recently, the best known IDO inhibitors ${ }^{18}$ displayed affinities in the micromolar range and comprised mainly Trp derivatives such as 1 -methyltryptophan $(\mathbf{1 M T})^{19}\left(K_{\mathrm{i}}=37 \mu \mathrm{M}\right)$ or $\beta$-carbolines $\left(K_{\mathrm{i}} \sim 0.12 \mathrm{mM}\right){ }^{20}$ Other indole-based IDO inhibitors, such as brassinin ${ }^{21,22}$ and methylthiohydantoin-tryptophan (MTH-Trp $)^{13}$ have been described. The best inhibitor of the brassinin class has a $K_{\mathrm{i}}$ of $12 \mu \mathrm{M}$ but is not Lipinski-compliant due to high hydrophobicity. ${ }^{22}$

In 2006, potent IDO inhibitors were isolated from marine invertebrate extracts, ${ }^{23,24}$ leading to two new series of uncompetitive nanomolar inhibitors. ${ }^{26,27}$ However, some of the most active compounds of the original series revealed to be inactive in a 
yeast-based cellular assay, suggesting poor cell penetration. ${ }^{7}$ This test nevertheless provided two new micromolar inhibitors with unknown modes of action.

In 1989, 4-phenylimidazole (PIM) was identified as a modestly potent IDO inhibitor. ${ }^{4,19}$ Despite the uncompetitive inhibition kinetics, the authors showed through spectroscopic studies that PIM binds into the active site of IDO. Moreover, they discovered a preferred binding of PIM to the inactive ferric $\left(\mathrm{Fe}^{3+}\right)$ form of the enzyme, which may explain this apparent discrepancy. The first crystal structure of human IDO complexed with the inhibitor reported later ${ }^{25}$ confirmed the binding of PIM in the active site. A recently undertaken structure-based study ${ }^{26}$ of PIM-derived molecules prompted by Sugimoto's work confirmed the antecedent findings while providing access to novel inhibitors with low micromolar potencies.

Recent developments in the field include hypoxic-neoplastic cells-targeting 1MT-tirapazamine hybrids, ${ }^{27}$ novel inhibitors obtained from marine sediments $\left(\mathrm{IC}_{50} \approx 2 \mu \mathrm{M}\right.$ ), ${ }^{28}$ potent competitive inhibitors including a hydroxyamidine chelating motif ( IC $_{50}$ values down to $60 \mathrm{nM}$ ), ${ }^{29}$ strong inhibition by modification of cysteine residues by ebselen, ${ }^{30}$ sub-micromolar $S$-benzylisothiourea-based inhibitors active in cells, ${ }^{31}$ various potent inhibitors ( $\mathrm{IC}_{50}$ values down to $0.2 \mu \mathrm{M}$ ) discovered by a combination of a docking-based pharmacophore model development and fragment-based drug design (FBDD). ${ }^{32}$

Despite all these efforts, modestly potent $\mathbf{1 M T}\left(K_{\mathrm{i}}=34 \mu \mathrm{M}\right)^{19}$ remains the only compound to have been passed into clinical trials as an IDO inhibitor so far. ${ }^{33}$ This prompted us to search for new scaffolds that could be further optimized with the objective of identifying potent and selective IDO inhibitors. Briefly, a collection of $\sim 62,000$ structures was downloaded from the ZINC website using Lipinski-style rules for fragments (molecular weight $\leq 250$, $\log P \leq 2.5$, number of rotatable bonds $\leq 5) .{ }^{34}$ These compounds were docked inside the IDO active site and ranked according to their best potential binding. From the 39 compounds that were selected, bought and assayed on IDO, six derivatives displayed an inhibitory potency $>30 \%$ at a concentration of $100 \mu \mathrm{M}$. Among these, compound $\mathbf{7 a}$, characterized by an indole nucleus substituted in the 2-position by a 2-pyridinyl-ethanone function, was our best hit (IDO IC $50 \sim 65 \mu \mathrm{M}$ ), with an inhibitory potency in the same range as the reference compound 1MT. (Table 1). Herein we report the synthesis and structure-activity study of compound 7a.

An initial docking study of 7a within the IDO binding cleft was performed by means of the automated GolD program ${ }^{35}$ and revealed essential features stabilizing $\mathbf{7 a}$ in the IDO binding cleft and particularly that (i) the oxygen atom of the ketone function, being situated $\sim 2 \AA$ above the plane of the heme, coordinates to the heme iron, (ii) the indole ring is found to be stabilized in the so-called lipophilic A-pocket of IDO. ${ }^{32}$ Indeed, this stabilization of the indole residue in Pocket $A$ was already suggested by other

Table 1

Inhibition of IDO activity by $\mathbf{1 M T}$ and 7a identified using VS

Compound Structure

groups in order to explain substrate binding as well as interaction of 1MT. In this position, the 3-pyridyl group is projected towards the entrance of the active site and is stabilized in the aromatic Pocket B through T-shape interactions with Phe163 and Phe226 (Fig. 1).

Our structural modifications of $\mathbf{7 a}$ were focused on exploiting three binding interactions with IDO: (1) the interior of the active site, in particular interactions with C129 and S167 in Pocket A; (2) the active site entrance region (Pocket B) occupied by the $\mathrm{N}$-cyclohexyl-2-aminoethanesulfonic acid (CHES) buffer molecule in a crystal structure; ${ }^{25}$ (3) the heme iron binding group. According to the binding orientation of 7a we hoped to achieve interactions in the interior region of the active site (Pocket A) by introducing substituents on the indole ring. The substituents were chosen with a view to balance on one side the lipophilic character of this Pocket introducing groups such as fluorine, bromine, chlorine, methyl; and, on the other side the possibility of forming H-bond interactions with specific amino acids with such substituents as hydroxyl, methoxy, nitro, or trifluoromethoxy. The interaction within Pocket $\mathrm{B}$ would be probed by replacement of the 3-pyridyl group of 7a with other (hetero)aromatics. The heme iron binding interaction would be explored by replacement of the ethanone moiety with other linkers between the indole and the aromatic side chain.

\section{Chemistry}

Initial efforts to prepare analogues of compound 7a included attempts to react indole-2-acyl chlorides (Scheme $1, \mathbf{3}, \mathrm{R}^{\prime \prime}=\mathrm{Cl}$ ) with reagents derived from 3-bromomethylpyridine hydrobromide under various conditions. ${ }^{36-38}$ In fact, all of these approaches revealed to be unsatisfactory, the main difficulty likely being the intrinsic instability of the in situ generated free base 3-bromomethylpyridine which readily oligomerizes. ${ }^{39}$ The only strategy allowing access to 7a analogues was the approach originally developed by Sundberg et al., as outlined in Scheme 1. This method involves the LDA effected deprotonation of alkylarene $\mathbf{1}$ followed by quenching of the in situ generated carbanion with a reactive indole carbonyl compound $\left(\mathbf{3}\right.$ and $\mathbf{6}$ ) at $0^{\circ} \mathrm{C}$. Stirring overnight while slowly attaining room temperature followed by aqueous workup, chromatographic purification and crystallization provided the targeted compounds.

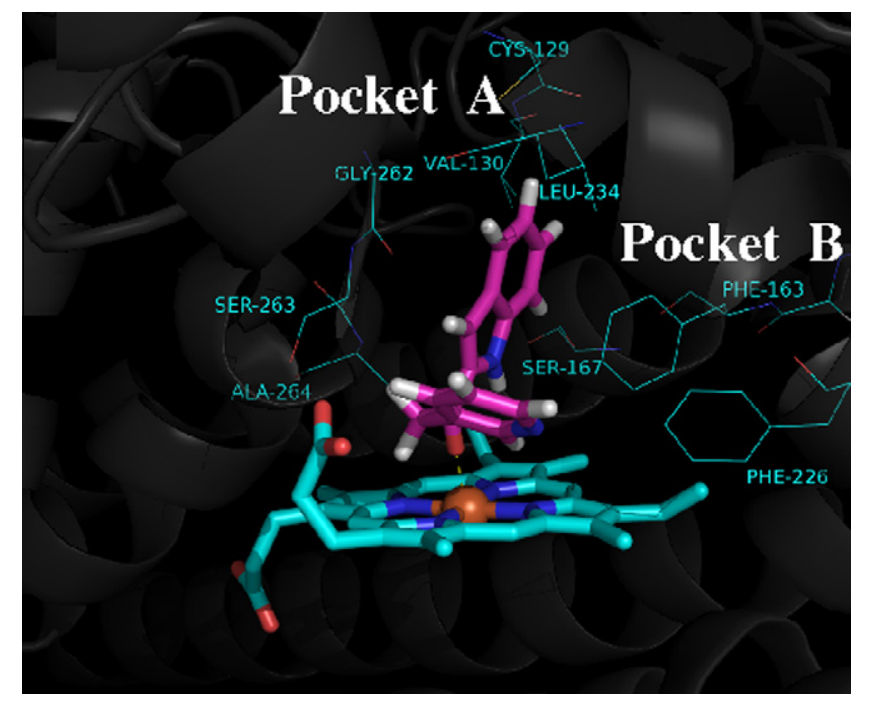

Figure 1. View of the lead compound 7a inside the IDO binding cleft. (Picture made with Pymol $^{34}$ ). 


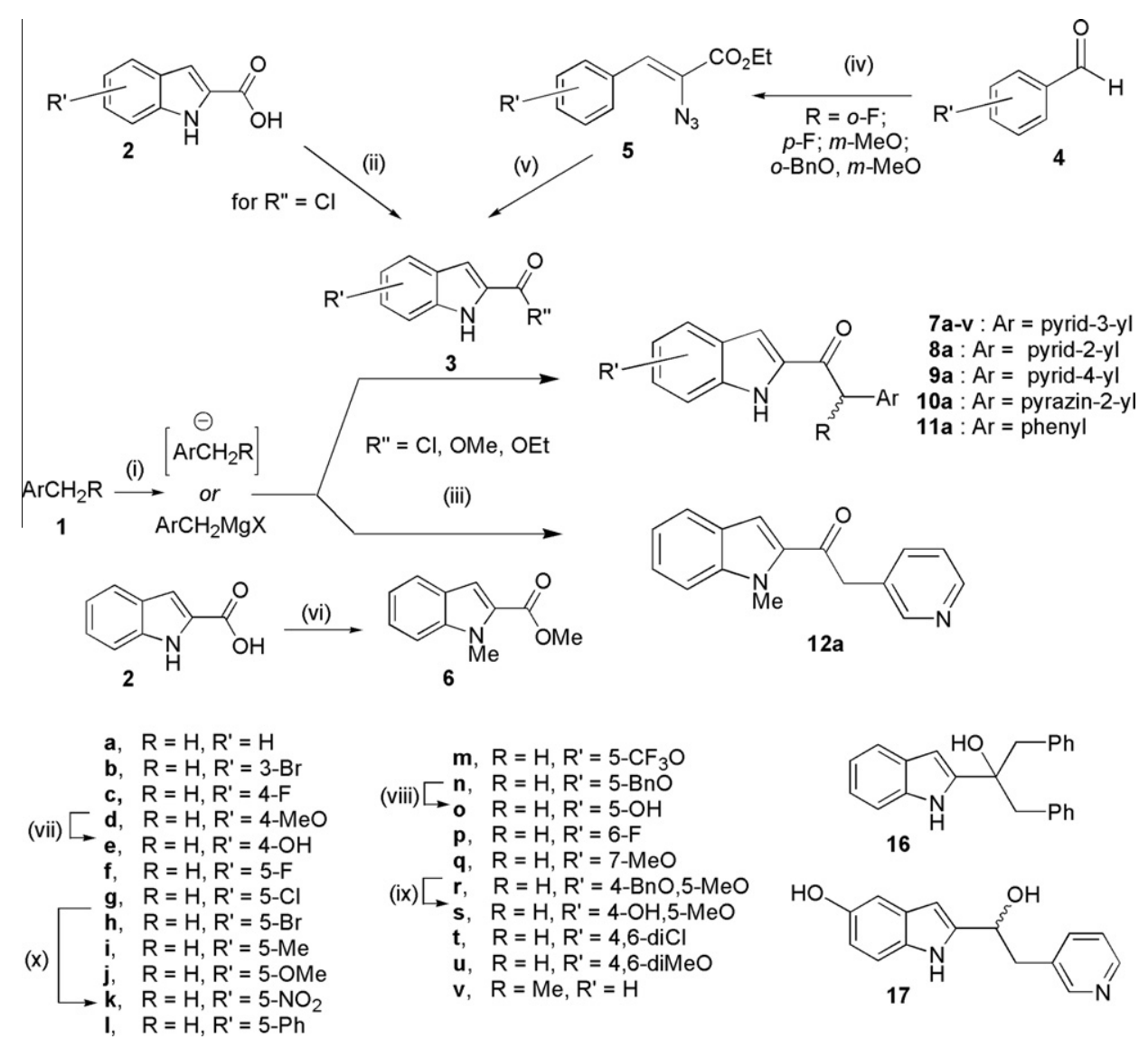

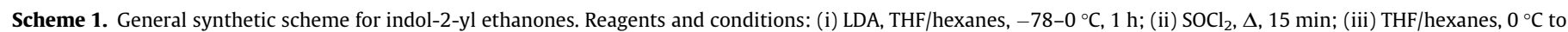

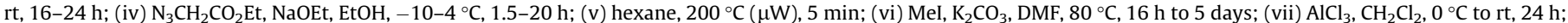

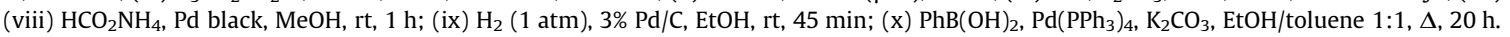

Accordingly, most of the compounds 7 as well as $\mathbf{8 a}, \mathbf{9 a}, \mathbf{1 0 a}$, and 11a were prepared from indole esters $\left(\mathbf{3}, \mathrm{R}^{\prime \prime}=\mathrm{OMe}, \mathrm{OEt}\right)$ or acyl chlorides $\left(3, \mathrm{R}^{\prime \prime}=\mathrm{Cl}\right)$ when these starting material were commercially available. Otherwise, the necessary indole acyl chloride 3 was prepared by reaction of the commercially available indole-2-carboxylic acid $\mathbf{2}$ in refluxing thionyl chloride. Non-commercially available indole esters $\mathbf{3}$ were made using the Hemetsberger-Knittel procedure starting from the corresponding $\boldsymbol{\alpha}$-azidocinnamates $\mathbf{5}$, which were in turn made by condensation of the substituted benzaldehydes $\mathbf{4}$ with ethyl azidoacetate under Knoevenagel conditions (Scheme 1) ${ }^{40,41}$ It should be noted that compound 11a (Scheme 1) was prepared in 37\% yield using commercial Grignard reagent in lieu of the LDA procedure. Moreover, during the course of this reaction, the tertiary alcohol $\mathbf{1 6}$ (inactive in the biological tests; data not shown) was also isolated in $17 \%$ yield.

Palladium catalyzed reductions were used to convert benzyloxysubstituted 2-ketoindoles $\mathbf{7 n}$ and $\mathbf{7 r}$ to their debenzylated counterparts 70 and 7s, respectively. Bis-alcohol 17 was also isolated as a byproduct during the catalytic reduction of $\mathbf{7 n}$. The 5 -phenylindole derivative $\mathbf{7 1}$ was prepared from the corresponding 5-bromo analogue $\mathbf{7 h}$ by a Suzuki cross-coupling with phenylboronic acid (Scheme 1). Finally, after initial unsuccessful attempts to demethylate 8d with boron tribromide (which seemed to cause product decomposition), the 4-hydroxyindole $\mathbf{8 e}$ was obtained by reaction of 8d with aluminum trichloride in dichloromethane.

For the synthesis of the $\mathrm{N}$-methylated analogue 12a, the required $\mathrm{N}$-methylated indole ester $\mathbf{6}$ was synthesized by dimethylation of $\mathrm{N}$-unsubstituted indole-2-carboxylic acid $\mathbf{2}$ (Scheme 1 ). ${ }^{42}$
The catalytic hydrogenation of $\mathbf{7 a}$ afforded the hydroxyl derivative 18 (Scheme 2). Compound 19 bearing an ethylene linker between the two aromatic rings was prepared from 7a by a

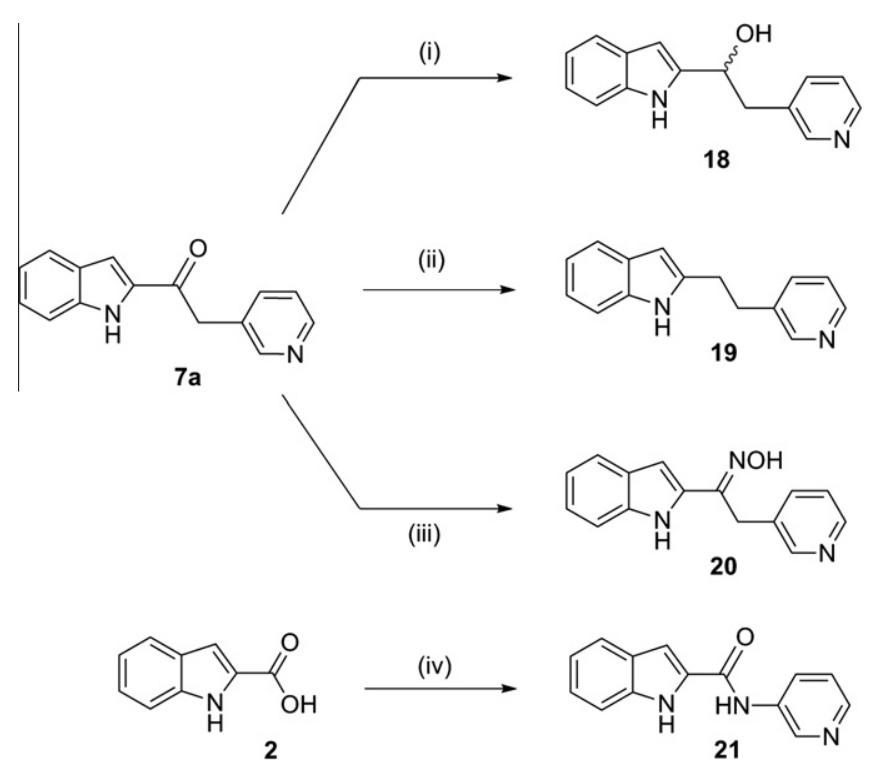

Scheme 2. Synthesis of compounds bearing different linker groups. Reagents and conditions: (i) $\mathrm{HCO}_{2} \mathrm{NH}_{4}$, Pd black, $\mathrm{MeOH}, \mathrm{rt}, 3$ days; (ii) $\mathrm{H}_{2} \mathrm{NNH}_{2}, \mathrm{KOH},\left(\mathrm{CH}_{2} \mathrm{OH}\right)_{2}$, $\mu \mathrm{W}, 1 \mathrm{~h}$ then aq $\mathrm{NH}_{4} \mathrm{Cl}$; (iii) $\mathrm{NH}_{2} \mathrm{OH} \cdot \mathrm{HCl}$, pyridine, $\mathrm{EtOH}, \mu \mathrm{W}\left(120^{\circ} \mathrm{C}\right), 30 \mathrm{~min}$; (iv) $\mathrm{SOCl}_{2}, \Delta, 15 \mathrm{~min}$ then 3 -aminopyridine, DIPEA, THF, $0^{\circ} \mathrm{C} \rightarrow \mathrm{rt}, 30 \mathrm{~min}$. 
Wolff-Kishner reduction. Oxime $\mathbf{2 0}$ was obtained by reacting ketone 7a with hydroxylamine. Finally, amide $\mathbf{2 1}$ was made from acid 2 by reaction with thionyl chloride followed by nucleophilic substitution with 3-aminopyridine (Scheme 2).

The structure of all compounds was confirmed by means of ${ }^{1} \mathrm{H}$, ${ }^{13} \mathrm{C}$ and (where applicable) ${ }^{19} \mathrm{~F}$ NMR, LC-MS, and elemental analysis (see Section 5). In addition, single crystal X-ray diffraction was used to corroborate the structures obtained in these series. The molecular structures of compounds $\mathbf{7 a}$ and $\mathbf{7 m}$ with displacement ellipsoids drawn at the $50 \%$ probability levels are depicted in Figure 2. It should be noted that for $\mathbf{7 m}$ thermal agitation of the trifluoromethoxy side chain led to large displacement ellipsoids for the fluorine atoms.

\section{Results}

\subsection{IDO inhibition through interactions in the interior of the active site (Pocket $\mathrm{A}$ )}

Detailed analysis of the binding conformation of 7a inside the IDO binding cleft suggests that introduction of small substituents around the indole scaffold could be beneficial for IDO inhibition.

Starting from our hit $7 \mathbf{a}\left(\mathrm{IC}_{50}=65 \mu \mathrm{M}\right)$, we first explored the influence of substitution around the indole ring. From Table 2 it can be observed that introduction of substituents in the 3- (7b), 4- (7c-e), and 7-position (7q) does not generally afford more potent compounds than the hit 7a. Substitutions in the 5- and 6 -positions are well tolerated and more potent compounds are obtained. Particularly, introducing a trifluoromethoxy group on the 5-position of the indole ring led to a fivefold improvement in the IDO inhibitory potency. Regarding the disubstitution, introductions of substituents in the 4,5- or the 4,6-positions do not drastically affect IDO inhibition. Finally, N-methylation of the indole nucleus seems to be tolerated as 12a is in vitro twofold more potent than parent compound $\mathbf{7 a}$.

\subsection{IDO inhibition through interactions with Pocket $B$ of the active site}

We next explored the influence of modifying the fragment interacting with Pocket B of the IDO active site. From Table 3, it can be observed that introductions of an unsubstituted phenyl (11a), a 2-pyridyl (8a) or a 2-pyrazinyl group (10a) in lieu of the 3-pyridyl moiety of 7a slightly improve the IDO inhibitory potency (IC 50 's of 29,37 , and $26 \mu \mathrm{M}$, respectively). On the contrary, introduction of a 4-pyridyl moiety (9a) afforded an inactive compound.

\subsection{IDO inhibition through interaction with the heme iron binding group}

Finally we appraised the importance of the ketone moiety of compound 7a in establishing an interaction with the heme iron. Indeed, reduction of this group (18) or its removal altogether (19) led to inactive compounds thus confirming the requirement for an iron coordinating group (Table 4). Oxime $\mathbf{2 0}$ is endowed with an in vivo
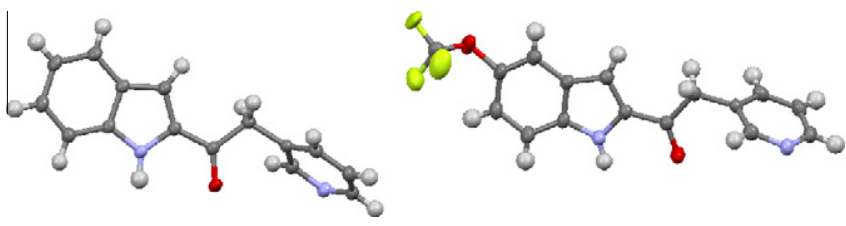

Figure 2. The molecular structures of (a) 7a and (b) 7m. Displacement ellipsoids are drawn at the $50 \%$ probability levels. (Pictures made with MERCURY 2.3 ).
Table 2

IDO inhibitory potency of compounds $7 \mathbf{a}-\mathbf{u}, \mathbf{1 2 a}$

\begin{tabular}{|c|c|c|c|c|}
\hline Compound & $\mathrm{R}$ & $\mathrm{R}_{1}$ & IDO IC ${ }_{50}(\mu \mathrm{M})$ & $\begin{array}{l}\text { IDO cell assay } \\
\text { inhibition } \% @ 20 \mu \mathrm{M}\end{array}$ \\
\hline $7 a$ & $\mathrm{H}$ & $\mathrm{H}$ & $65 \pm 7$ & 13 \\
\hline $7 \mathbf{b}$ & $3-\mathrm{Br}$ & $\mathrm{H}$ & $\mathrm{NI}$ & $\mathrm{NI}^{*}$ \\
\hline 7c & $4-F$ & $\mathrm{H}$ & $153 \pm 23$ & 12 \\
\hline 7d & 4-MeO & $\mathrm{H}$ & $58 \pm 5$ & $\mathrm{NI}$ \\
\hline $7 e$ & $4-\mathrm{OH}$ & $\mathrm{H}$ & $83 \pm 18$ & $\mathrm{NI}$ \\
\hline $7 f$ & $5-\mathrm{F}$ & $\mathrm{H}$ & $36.0 \pm 0.1$ & 24 \\
\hline $7 \mathrm{~g}$ & $5-\mathrm{Cl}$ & $\mathrm{H}$ & $24.6 \pm 0.1$ & 24 \\
\hline 7h & $5-\mathrm{Br}$ & $\mathrm{H}$ & $18 \pm 1$ & $\mathrm{NI}$ \\
\hline $7 \mathbf{i}$ & 5-Me & $\mathrm{H}$ & $87 \pm 11$ & 21 \\
\hline $7 \mathbf{j}$ & 5-OMe & $\mathrm{H}$ & $49 \pm 1$ & $\mathrm{NT}^{* *}$ \\
\hline 7k & $5-\mathrm{NO}_{2}$ & $\mathrm{H}$ & NI & $\mathrm{NI}$ \\
\hline 71 & $5-\mathrm{Ph}$ & $\mathrm{H}$ & $96 \pm 1$ & $\mathrm{NI}$ \\
\hline $7 \mathrm{~m}$ & $5-\mathrm{CF}_{3} \mathrm{O}$ & $\mathrm{H}$ & $13.1 \pm 0.1$ & 12 \\
\hline 70 & $5-\mathrm{OH}$ & $\mathrm{H}$ & $37 \pm 3$ & $\mathrm{NI}$ \\
\hline $7 p$ & $6-\mathrm{F}$ & $\mathrm{H}$ & $43 \pm 7$ & $\mathrm{NI}$ \\
\hline $7 q$ & 7-MeO & $\mathrm{H}$ & $82 \pm 5$ & 6 \\
\hline $7 \mathbf{r}$ & 4-BnO, 5-MeO & $\mathrm{H}$ & NI & $\mathrm{NI}$ \\
\hline $7 s$ & 4-OH, 5-MeO & $\mathrm{H}$ & $63 \pm 3$ & 11 \\
\hline $7 t$ & 4,6-DiCl & $\mathrm{H}$ & $139 \pm 12$ & $\mathrm{NI}$ \\
\hline $7 \mathbf{u}$ & 4,6-DiMeO & $\mathrm{H}$ & $45 \pm 8$ & Toxic \\
\hline $12 a$ & $\mathrm{H}$ & $\mathrm{Me}$ & $34 \pm 2$ & $\mathrm{NI}$ \\
\hline
\end{tabular}

** NT $=$ not tested.

$\mathrm{NI}=$ no inhibition.

Table 3

IDO inhibitory potency of compounds 7a-11a

Compound

$\mathrm{NI}=$ no inhibition.

inhibitory potency similar to that of ketone 7a but surprisingly, this compound is not active in vitro. This might result from a poor stability of the oxime moiety in the experimental conditions of the assay. Introducing a methyl group in the ethanone linker $(\mathbf{7 v})$ or its replacement with an amide (21) afforded less potent compounds.

\section{Discussion and conclusion}

About 30 original compounds were synthesized around the indol-2-yl ethanone scaffold and their in vivo and in vitro inhibitory potency against indoleamine 2,3-dioxygenase (IDO) was evaluated. Starting from the hit (1H-indol-2-yl)-2-pyridin-3- 
Table 4

IDO inhibitory potency of compounds $7 a, 7 v, 18-21$

\begin{tabular}{|c|c|c|c|}
\hline Compound & Structure & IDO IC $_{50}(\mu \mathrm{M})$ & IDO cell assay inhibition \% @ $20 \mu \mathrm{M}$ \\
\hline $7 a$ & & $65 \pm 7$ & 13 \\
\hline $7 \mathbf{v}$ & & $141 \pm 4$ & $\mathrm{NI}$ \\
\hline 18 & & $\mathrm{NI}$ & $\mathrm{NI}$ \\
\hline 19 & & $\mathrm{NI}$ & $\mathrm{NI}$ \\
\hline 20 & & $19.4 \% @ 100 \mu \mathrm{M}$ & 25 \\
\hline 21 & & $94 \pm 2$ & $\mathrm{NI}$ \\
\hline
\end{tabular}

$\mathrm{NI}=$ no inhibition.

yl-ethanone (7a) identified through a virtual screening procedure and possessing an $\mathrm{IC}_{50}$ of $65 \mu \mathrm{M}$ in the in vitro test, a fivefold improvement in potency $\left(\mathrm{IC}_{50}=13 \mu \mathrm{M}\right)$ could be achieved by introducing a trifluoromethoxy group in the 5-position of the indole nucleus. Most small substituents around the indole moiety led to compounds of roughly equivalent potency, indicating room for further modifications but also a probable lack of close interactions of the inhibitor molecules with the IDO Pocket A interior as described by Rohrig et al. ${ }^{32} \mathrm{~A}$ similar generalization can be applied to the other aromatic moiety and its putative interactions with Pocket B of the IDO. Altogether, it seems no strong H-bond interactions with any of the hydrogen bonding residues in the IDO active site could be established. The presence of an iron chelating group seems to be of crucial importance, since its deletion leads to loss of potency.

A number of compounds investigated here possess a moderate in vivo activity. The compounds $\mathbf{7 f}$ and $\mathbf{7 g}$ (with small halogen atoms in the 5-position of the indole moiety) are both endowed with $24 \%$ IDO inhibition at a $20 \mu \mathrm{M}$ concentration in the cellular assay, which indicates reasonable cell penetration. A very similar value was obtained for oxime $\mathbf{2 0}$.

In summary, a novel series of compounds with a moderate inhibitory activity against IDO has been identified. Both in vitro and in vivo assays show promising results. Further modifications aiming to achieve more favorable interactions with the enzyme active site are in due course.

\section{Experimental part}

\subsection{Chemistry}

\subsubsection{General experimental procedures}

Chemicals were purchased from commercial suppliers (Acros, Sigma-Aldrich, Maybridge, Apollo) and used without further purification. All solvents were used as purchased from Acros, Sigma-Aldrich, Fisher Scientific and Biosolve. All reactions were performed under an inert argon (Alphagaz 2) atmosphere, unless stated otherwise. Melting points were determined in open capillar- ies on a Büchi B-540 capillary melting point apparatus and are uncorrected.

Thin layer chromatography (TLC) was performed on silica gel plates $\left(60 \mathrm{~F}_{254}, 0.2 \mathrm{~mm}\right.$ thick, Merck) eluting with gradients of ethyl acetate in cyclohexane. The spots were visualized by ultraviolet light (wavelengths 254 and $366 \mathrm{~nm}$ ).

${ }^{1} \mathrm{H}$ NMR spectra were recorded in DMSO- $d_{6}$ solutions on a Jeol JNM EX 400 machine at $400 \mathrm{MHz}$ with tetramethylsilane (TMS) as internal standard. ${ }^{13} \mathrm{C}$ and ${ }^{19} \mathrm{~F}$ NMR spectra were recorded on the same machine in DMSO- $d_{6}$ solutions at $100 \mathrm{MHz}$ and $376.2 \mathrm{MHz}$, respectively. Chemical shifts $(\delta)$ are reported in ppm downfield from TMS.

Elemental analyses (C, H, N, S) were performed on a Thermo Finnigan FlashEA 1112 apparatus.

Analytical LC-MS analyses were performed on an Agilent 1100 Series LC-MSD Trap system using UV detection at 254 and $366 \mathrm{~nm}$. MS data were recorded using electrospray ionization (ESI) operating in positive mode. The following two methods were applied: method 1: injection of $10 \mu \mathrm{l}$ of a $20 \mu \mathrm{g} / \mathrm{mL}$ acetonitrile solution onto a C18-3.5 $\mu \mathrm{m}$ Zorbax SB column $(100 \times 3 \mathrm{~mm})$; separation using a gradient (flow rate: $0.5 \mathrm{~mL} / \mathrm{min}$ ) of acetonitrile in acetic acid $0.1 \%(\mathrm{v} / \mathrm{v})$ in water: $5-95 \%$ acetonitrile during $5 \mathrm{~min}$, holding for $3 \mathrm{~min}$, then reversing to $5 \%$ acetonitrile during $0.1 \mathrm{~min}$ and holding for an additional $5.4 \mathrm{~min}$. Method 2: injection of $10 \mu \mathrm{l}$ of a $2 \mu \mathrm{g} / \mathrm{mL}$ acetonitrile solution onto a C18-5 $\mu \mathrm{m}$ Agilent LiChrospher 100 column $(250 \times 4 \mathrm{~mm})$; separation using a gradient (flow rate: $1.0 \mathrm{~mL} / \mathrm{min}$ ) of acetonitrile in acetic acid $0.1 \%(\mathrm{v} / \mathrm{v})$ in water: $20-80 \%$ acetonitrile during $20 \mathrm{~min}$, holding for $20 \mathrm{~min}$, then reversing to $20 \%$ acetonitrile during $0.1 \mathrm{~min}$ and holding for an additional $5 \mathrm{~min}$.

Automated flash chromatography was performed on the Biotage AB (Uppsala, Sweden) SP1 system equipped with pre-packed flash KP-Sil silica cartridges eluting with gradients of ethyl acetate in cyclohexane. The peaks were detected by UV absorption at 254 and $320 \mathrm{~nm}$.

The yields refer to combined yields of chromatographically and spectroscopically pure ( $>95 \%)$ compounds and the crops obtained by evaporation of mother liquors. All new compounds were determined to be $>95 \%$ pure by LC-MS and NMR. 
The microwave-assisted syntheses were carried out in an Initiator 16 single-mode microwave instrument producing controlled irradiation at $2.450 \mathrm{GHz}$ (Biotage $\mathrm{AB}$ ). Reaction times refer to hold times at the temperatures indicated, not to total irradiation times. The temperature was measured with an IR sensor on the outside of the reaction vessel.

\subsubsection{Methods for preparation of indolic intermediates ( 3 and} 6)

5.1.2.1. Indole-2-acyl chlorides $\left(3, \mathbf{R}^{\prime \prime}=\mathbf{C l}\right)$. Commercial indole2-carboxylic acid was dissolved in thionyl chloride $(\sim 1.5 \mathrm{~mL} /$ $\mathrm{mmol}$ ) and the suspension was boiled for $15 \mathrm{~min}$, during which time typically a dark green solution was formed. Excess thionyl chloride was removed under reduced pressure and the solid residue was suspended in toluene and the suspension was evaporated to dryness (toluene treatment was repeated three times). The greengrayish solid residues were used without further purification.

5.1.2.2. Indolic esters by Hemetsberger-Knittel synthesis (3, $\left.\mathbf{R}^{\prime \prime}=\mathbf{0 E t}\right)^{\mathbf{4 0 , 4 1}}$. Sodium (4.0 equiv) was dissolved in absolute ethanol $(0.5 \mathrm{~mL} / \mathrm{mmol})$ and the solution was cooled to $-10^{\circ} \mathrm{C}$ in an ice/ acetone bath. A corresponding benzaldehyde (1.0 equiv) was dissolved in a commercial $25 \%$ solution of ethyl azidoacetate in ethanol ( $2.1 \mathrm{~g}$ per mmol of starting benzaldehyde, 4.0 equiv) and this solution was added dropwise to the sodium ethoxide solution during $30 \mathrm{~min}$ while the bath temperature was kept at $-10^{\circ} \mathrm{C}$. The reaction mixtures typically turned into bright yellow suspensions. The stirring was continued until TLC (developing with 15\% EtOAC in cyclohexane) indicated completion or the reaction (1.5-2.5 h). If the reaction required more than $1.5 \mathrm{~h}$, the temperature was allowed to rise to $0^{\circ} \mathrm{C}$. In one case $(\mathbf{5 r})$, the reaction had to be run overnight. The mixtures were partitioned between ethyl acetate and water. The aqueous phase was extracted twice with ethyl acetate and the organic layers were pooled, washed with brine, dried over magnesium sulfate, and concentrated under reduced pressure to provide crude azidoacrylic esters (5) as yellow to orange oils or liquids in a $46-100 \%$ yield. These products were suspended in $n$-hexane (6-9 $\mathrm{mL} / \mathrm{mmol}$ of crude azidoacrylic ester) and subjected to microwave heating at $200{ }^{\circ} \mathrm{C}$ for $5 \mathrm{~min}(P=100-140 \mathrm{~W}, p=12-$ 13 bar). The resulting residues were taken into ethyl acetate and evaporated with silica gel. The corresponding indolic esters 3 (yields 19-93\%) were purified by chromatography. In one case, a mixture of isomers was obtained. 2-Azido-3-(3-methoxyphenyl)acrylic acid ethyl ester gave 5-methoxy-1H-indole-2-carboxylic acid ethyl ester (3j) and 7-methoxy-1H-indole-2-carboxylic acid ethyl ester (3q) in a 1:1 ratio (each in a $47 \%$ yield).

5.1.2.3. N-Methylated indolic ester; methyl 1-methyl-1H-indole2-carboxylate (6). Prepared according to a literature procedure. ${ }^{42}$ Methyl iodide $(5.0 \mathrm{~mL}, 80.0 \mathrm{mmol})$ was added to a stirred suspension of anhydrous potassium carbonate $(6.3 \mathrm{~g}, 45.6 \mathrm{~mol})$ and $1 \mathrm{H}$ indole-2-carboxylic acid $(2 ; 5.3 \mathrm{mmol})$ in dry DMF $(6 \mathrm{~mL})$ and the mixture was stirred at $80^{\circ} \mathrm{C}$ until the reaction was complete as indicated by TLC and/or LC-MS (3-5 days). Upon cooling to room temperature, the suspension was partitioned between ethyl acetate and water. The aqueous phase was extracted with ethyl acetate and the combined organic layers were dried over $\mathrm{MgSO}_{4}$, concentrated under reduced pressure and dried to yield the desired N-methylated indole ester (6) as a beige solid in a $96-99 \%$ yield.

\subsubsection{General synthetic procedure for 1 - $(1 H$-indol-2-yl)-2-aryl- ketones $(7-10,12)^{43}$}

An oven-dried flask was purged with argon while hot, then allowed to cool down to room temperature under argon and charged with dry THF ( $2 \mathrm{~mL} / \mathrm{mmol}$ of starting indole $\mathbf{3 / 6}$ ) and diiso- propylamine (4.0 equiv). The solution was cooled to $-78^{\circ} \mathrm{C}$ in a dry ice/isopropanol bath and $n$-butyl lithium, $1.6 \mathrm{M}$ solution in hexanes ( 4.0 equiv), was added to give a bright yellow solution. The mixture was stirred for $30 \mathrm{~min}$ below $-60{ }^{\circ} \mathrm{C}$ whereupon a solution of picoline or another appropriate reagent with an ionizable methyl(ene) group (4.0 equiv) in THF ( $2 \mathrm{~mL} / \mathrm{mmol}$ of starting indole 3 or $\mathbf{6}$ ) was added to give a yellow to red colored mixture. During a further $30 \mathrm{~min}$, the bath temperature was allowed to rise to approx. $0{ }^{\circ} \mathrm{C}$ during which time the reaction mixture became a yellow to red suspension. The temperature was then kept at $0{ }^{\circ} \mathrm{C}$ (using an ice/water bath) for an additional $30 \mathrm{~min}$. At this point, a solution of the indole-2-carbonyl compound $\mathbf{3 / 6}$ (1.0 equiv) in THF $(4 \mathrm{~mL} / \mathrm{mmol})$ was added dropwise over the flask wall. The reaction mixture darkened (dark purple to dark brown color in most cases) and was then allowed to attain room temperature overnight. At $18 \mathrm{~h}$ (unless otherwise stated) after the addition of the indole component, the reaction was quenched with saturated aqueous ammonium chloride solution $(10 \mathrm{~mL} / \mathrm{mmol}$ of starting compound 3/6) and stirred for several minutes. Upon partition between ethyl acetate and water, the aqueous phase was extracted twice with dichloromethane and the combined organic layers were dried over $\mathrm{MgSO}_{4}$. The title products were purified by chromatography (the products typically eluted with $70-80 \%$ of ethyl acetate). The products were then precipitated by concentration of the pooled column fractions combined with the addition of cyclohexane. The precipitates formed were filtered off, washed twice with cyclohexane and dried at $40^{\circ} \mathrm{C}$ in vacuo to yield analytically pure samples. The following compounds were prepared in this way:

5.1.3.1. 1-(1H-Indol-2-yl)-2-pyridin-3-yl-ethanone (7a $)^{\mathbf{4 3 - 4 5}}$. Prepared from commercial $1 H$-indole-2-carboxylic acid ethyl ester 3a (986 mg, $5.05 \mathrm{mmol}$ ) and 3-picoline. Yellowish solid (699 mg, $59 \%$ ), mp $177-180^{\circ} \mathrm{C}$. LC-MS $R_{\mathrm{t}} 5.2 \mathrm{~min}$ (method 1), $7.0 \mathrm{~min}$ (method 2); $\mathrm{m} / \mathrm{z}\left[\mathrm{MH}^{+}\right]$237. ${ }^{1} \mathrm{H}$ NMR $\delta 11.76(1 \mathrm{H}$, br s, indole$\mathrm{H} 1), 8.53(1 \mathrm{H}, \mathrm{d}, J=1.7 \mathrm{~Hz}, \operatorname{ArH}), 8.43(1 \mathrm{H}, \mathrm{dd}, J=4.8,1.7 \mathrm{~Hz}$, $\operatorname{ArH}), 7.71(1 \mathrm{H}, \mathrm{d}, J=7.8 \mathrm{~Hz}, \operatorname{ArH}), 7.69(1 \mathrm{H}, \mathrm{d}, J=7.8 \mathrm{~Hz}, \operatorname{ArH})$, $7.56(1 \mathrm{H}, \mathrm{d}, J=1.8 \mathrm{~Hz}, \operatorname{ArH}), 7.41(1 \mathrm{H}, \mathrm{d}, J=8.2 \mathrm{~Hz}, \operatorname{ArH}), 7.33$ $(1 \mathrm{H}, \mathrm{dd}, J=7.8,4.8 \mathrm{~Hz}, \operatorname{ArH}), 7.26(1 \mathrm{H}, \mathrm{t}, J=7.6 \mathrm{~Hz}, \operatorname{ArH}), 7.06$ $(1 \mathrm{H}, \mathrm{t}, J=7.6 \mathrm{~Hz}, \operatorname{ArH}), 4.36\left(2 \mathrm{H}, \mathrm{s}, \mathrm{CH}_{2}\right) .{ }^{13} \mathrm{C} \mathrm{NMR} \delta 190.1(\mathrm{C}=\mathrm{O})$, 151.1 (ArC), 148.3 (ArC), $138.6(\operatorname{ArC}), 137.8(\operatorname{ArC}), 135.4(\operatorname{ArC})$, 131.6 (ArC), 127.4 (ArC), 126.2 (ArC), $124.0(\operatorname{ArC}), 123.3$ (ArC), 120.9 (ArC), 113.3 (ArC), 110.7 (ArC), $42.0\left(\mathrm{CH}_{2}\right)$. Anal. Calcd for $\mathrm{C}_{15} \mathrm{H}_{12} \mathrm{~N}_{2} \mathrm{O}$ : C, 76.25; H, 5.12; N, 11.86. Found: C, 76.16; H, 5.13; $\mathrm{N}, 11.87$.

5.1.3.2. 1-(3-Bromo-1H-indol-2-yl)-2-pyridin-3-yl-ethanone (7b). Prepared from commercial 3-bromo- $1 \mathrm{H}$-indole-2-carboxylic acid (267 mg, $1.09 \mathrm{mmol}$ ) and 3-picoline via corresponding acyl chloride 3b (method A). Bright yellow solid (100 mg, 29\%), mp 194$195{ }^{\circ} \mathrm{C}$ (dec). LC-MS $R_{\mathrm{t}} 6.0 \mathrm{~min}$ (method 1), $12.8 \mathrm{~min}$ (method 2); $m / z\left[\mathrm{MH}^{+}\right] 315 ; 317 .{ }^{1} \mathrm{H}$ NMR $\delta 12.19(1 \mathrm{H}$, br s, indole-H1), 8.49 $(1 \mathrm{H}, \mathrm{d}, J=1.8 \mathrm{~Hz}, \mathrm{ArH}), 8.45(1 \mathrm{H}, \mathrm{dd}, J=4.8 \mathrm{~Hz}, 1.6, \operatorname{ArH}), 7.69$ $(1 \mathrm{H}, \mathrm{d}, J=7.8 \mathrm{~Hz}, \mathrm{ArH}), 7.57(1 \mathrm{H}, \mathrm{d}, J=8.0 \mathrm{~Hz}, \operatorname{ArH}), 7.49(1 \mathrm{H}, \mathrm{d}$, $J=8.2 \mathrm{~Hz}, \mathrm{ArH}), 7.38-7.33(2 \mathrm{H}$, overlapped, $2 \mathrm{ArH}), 7.19(1 \mathrm{H}, \mathrm{t}$, $J=7.6 \mathrm{~Hz}, \mathrm{ArH}), 4.53\left(2 \mathrm{H}, \mathrm{s}, \mathrm{CH}_{2}\right) .{ }^{13} \mathrm{C}$ NMR $\delta 189.3(\mathrm{C}=\mathrm{O}), 151.4$ (ArC), 148.4 (ArC), $138.2(\operatorname{ArC}), 136.5$ (ArC), 132.1 (ArC), 130.8 (ArC), 127.6 (ArC), 127.3 (ArC), 123.9 (ArC), 122.0 (ArC), 121.2 (ArC), 113.7 (ArC), $96.5(\operatorname{ArC}), 44.4\left(\mathrm{CH}_{2}\right)$. Anal. Calcd for $\mathrm{C}_{15} \mathrm{H}_{11} \mathrm{BrN}_{2} \mathrm{O}$ : C, 57.16; H, 3.52; N, 8.89. Found: C, 58.26; H, 3.57; $\mathrm{N}, 8.48$.

5.1.3.3. 1-(4-Fluoro-1H-indol-2-yl)-2-pyridin-3-yl-ethanone (7c). Prepared from 4-fluoro-1H-indole-2-carboxylic acid ethyl ester 3c (method B; $184 \mathrm{mg}, 0.89 \mathrm{mmol}$ ) and 3-picoline. Yellow half-solid (15 mg, 7\%). LC-MS $R_{\mathrm{t}} 5.4 \mathrm{~min}(\operatorname{method} 1) ; \mathrm{m} / z\left[\mathrm{MH}^{+}\right] 255 .{ }^{1} \mathrm{H}$ NMR $\delta 12.10(1 \mathrm{H}$, br s, indole-H1), $8.53(1 \mathrm{H}$, br s, ArH $), 8.43(1 \mathrm{H}$, 
$\mathrm{d}, J=4.1 \mathrm{~Hz}, \mathrm{ArH}), 7.73-7.65$ (2H, overlapped, $2 \mathrm{ArH}), 7.33(1 \mathrm{H}, \mathrm{dd}$, $J=7.2,5.1 \mathrm{~Hz}, \mathrm{ArH}), 7.24(2 \mathrm{H}$, overlapped, $2 \mathrm{ArH}), 6.85(1 \mathrm{H}, \mathrm{m}$, ArH), $4.40\left(2 \mathrm{H}, \mathrm{s}, \mathrm{CH}_{2}\right) .{ }^{13} \mathrm{C}$ NMR $\delta 190.2(\mathrm{C}=\mathrm{O}), 167.5(\mathrm{ArC})$, $149.8\left(\mathrm{~d}, J_{\mathrm{CF}}=278 \mathrm{~Hz}\right.$, indole-C4), 137.8 (ArC), 135.7 (ArC), 132.2 (d, overlapped, ArC), 132.1 ( $\operatorname{ArC}), 129.2(\operatorname{ArC}), 126.8\left(\mathrm{~d}, J_{\mathrm{CF}}=10 \mathrm{~Hz}\right.$, ArC), 124.0 (ArC), 116.9 (d, $\left.J_{\mathrm{CF}}=22 \mathrm{~Hz}, \operatorname{ArC}\right), 109.9$ (ArC), 106.0 $(\operatorname{ArC}), 105.0\left(\mathrm{~d}, J_{\mathrm{CF}}=18 \mathrm{~Hz}, \operatorname{ArC}\right), 42.0\left(\mathrm{CH}_{2}\right)$.

5.1.3.4. 1-(4-Methoxy-1H-indol-2-yl)-2-pyridin-3-yl-ethanone (7d). Prepared from commercial 4-methoxy- $1 \mathrm{H}$-indole-2-carboxylic acid methyl ester 3d (268 mg, $1.29 \mathrm{mmol}$ ) and 3-picoline. White solid (238 mg, 69\%), mp $159-160{ }^{\circ} \mathrm{C}$ (dec). LC-MS $R_{\mathrm{t}}$ 5.3 min (method 1 ); $m / z\left[\mathrm{MH}^{+}\right] 267 .{ }^{1} \mathrm{H}$ NMR $\delta 11.75(1 \mathrm{H}$, br s, indole-H1 $), 8.52(1 \mathrm{H}$, br s, ArH $), 8.42(1 \mathrm{H}, \mathrm{d}, J=4.9 \mathrm{~Hz}, \mathrm{ArH}), 7.70(1 \mathrm{H}$, $\mathrm{d}, J=7.8 \mathrm{~Hz}, \mathrm{ArH}), 7.57(1 \mathrm{H}, \mathrm{br} \mathrm{s}, \mathrm{ArH}), 7.32(1 \mathrm{H}, \mathrm{dd}, J=7.6,4.9 \mathrm{~Hz}$, ArH), $7.17(1 \mathrm{H}, \mathrm{t}, J=8.1 \mathrm{~Hz}, \mathrm{ArH}), 6.97(1 \mathrm{H}, \mathrm{d}, J=8.1 \mathrm{~Hz}, \mathrm{ArH}), 6.51$ $(1 \mathrm{H}, \mathrm{d}, J=7.6 \mathrm{~Hz}, \mathrm{ArH}), 4.33\left(2 \mathrm{H}, \mathrm{s}, \mathrm{CH}_{2}\right), 3.88\left(3 \mathrm{H}, \mathrm{s}, \mathrm{OCH}_{3}\right) .{ }^{13} \mathrm{C}$ NMR $\delta 189.7(\mathrm{C}=\mathrm{O}), 154.9(\operatorname{ArC}), 151.1(\operatorname{ArC}), 148.3(\operatorname{ArC}), 139.9$ (ArC), 137.7 (ArC), 134.3 (ArC), 131.8 (ArC), 127.5 (ArC), 123.9 (ArC), 118.8 (ArC), 108.3 (ArC), 106.1 (ArC), 100.0 (ArC), 55.6 $\left(\mathrm{OCH}_{3}\right), 41.8\left(\mathrm{CH}_{2}\right)$. Anal. Calcd for $\mathrm{C}_{16} \mathrm{H}_{14} \mathrm{~N}_{2} \mathrm{O}_{2}$ : C, 72.16; H, 5.30; $\mathrm{N}, 10.52$. Found: C, 72.36; H, 5.30; N, 10.36.

5.1.3.5. 1-(4-Hydroxy-1H-indol-2-yl)-2-pyridin-3-yl-ethanone (7e). A solution of methoxyindole $7 \mathbf{d}(143 \mathrm{mg}, 0.54 \mathrm{mmol})$ in dry dichloromethane $(5 \mathrm{~mL})$ was cooled to $0{ }^{\circ} \mathrm{C}$ and anhydrous aluminum chloride ( $247 \mathrm{mg}, 1.84 \mathrm{mmol}$ ) was added to give a yellow suspension. Room temperature was slowly attained while the color of the reaction mixture gradually changed to dark red. After $19 \mathrm{~h}$, as TLC still indicated presence of the starting compound, another aliquot of aluminum chloride and $2 \mathrm{~mL}$ of dichloromethane were added. At $24 \mathrm{~h}$ of total reaction time (most of the starting compound still unreacted), the mixture was partitioned between ethyl acetate and water. The aqueous phase was extracted with ethyl acetate and the combined organic layers were washed with brine and dried over magnesium sulfate. Chromatographic purification (the title product eluted with 95-100\% ethyl acetate) yielded alcohol ed $140-3$ as an off-white solid (11 mg, 8\%). LC-MS $R_{\mathrm{t}} 4.3 \mathrm{~min}$ (method 1); $m / z\left[\mathrm{MH}^{+}\right] 253 .{ }^{1} \mathrm{H}$ NMR $\delta 11.59(1 \mathrm{H}$, br s, indoleH1), $9.88(1 \mathrm{H}$, br s, OH), $8.52(1 \mathrm{H}, \mathrm{d}, J=1.8 \mathrm{~Hz}, \mathrm{ArH}), 8.42(1 \mathrm{H}$, dd, $J=4.6,1.4 \mathrm{~Hz}, \operatorname{ArH}), 7.70(1 \mathrm{H}, \mathrm{d}, J=7.6 \mathrm{~Hz}, \operatorname{ArH}), 7.57(1 \mathrm{H}, \mathrm{d}$, $J=1.6 \mathrm{~Hz}, \operatorname{ArH}), 7.32(1 \mathrm{H}, \mathrm{dd}, J=7.3,4.6 \mathrm{~Hz}, \operatorname{ArH}), 7.03(1 \mathrm{H}, \mathrm{t}$, $J=8.0 \mathrm{~Hz}, \operatorname{ArH}), 6.82(1 \mathrm{H}, \mathrm{d}, J=8.3 \mathrm{~Hz}, \operatorname{ArH}), 6.37(1 \mathrm{H}, \mathrm{d}$, $J=7.6 \mathrm{~Hz}, \mathrm{ArH}), 4.32\left(2 \mathrm{H}, \mathrm{s}, \mathrm{CH}_{2}\right) .{ }^{13} \mathrm{C}$ NMR $\delta 189.5(\mathrm{C}=\mathrm{O}), 153.1$ (ArC), 151.1 (ArC), 148.3 (ArC), 140.5 (ArC), 137.7 (ArC), 134.0 (ArC), 131.8 (ArC), 127.6 (ArC), 123.9 (ArC), 118.7 (ArC), 108.7 (ArC), 104.1 (ArC), 103.9 ( $\mathrm{ArC}), 41.9\left(\mathrm{CH}_{2}\right)$.

5.1.3.6. 1-(5-Fluoro-1H-indol-2-yl)-2-pyridin-3-yl-ethanone (7f). Prepared from commercial 5-fluoro- $1 \mathrm{H}$-indole-2-carboxylic acid (186 mg, $1.02 \mathrm{mmol}$ ) and 3-picoline via corresponding acyl chloride 3f (method A). Yellowish solid (62 mg, 24\%), mp 194-197 ${ }^{\circ} \mathrm{C}$ LC-MS $R_{\mathrm{t}} 5.3$ min (method 1 ); $m / z\left[\mathrm{MH}^{+}\right] 255 .{ }^{1} \mathrm{H}$ NMR $\delta 11.88$ $(1 \mathrm{H}$, br s, indole-H1), $8.51(1 \mathrm{H}, \mathrm{br} \mathrm{s}, \mathrm{ArH}), 8.43(1 \mathrm{H}, \mathrm{d}, J=4.8 \mathrm{~Hz}$, $\operatorname{ArH}), 7.70(1 \mathrm{H}, \mathrm{d}, J=7.8 \mathrm{~Hz}, \operatorname{ArH}), 7.53(1 \mathrm{H}, \mathrm{br} \mathrm{s}, \operatorname{ArH}), 7.46(1 \mathrm{H}$, dd, $\left.{ }^{3} J_{\mathrm{HF}}=9.6 \mathrm{~Hz},{ }^{4} J_{\mathrm{HH}}=2.1 \mathrm{~Hz}, \operatorname{ArH}\right), 7.42\left(1 \mathrm{H}, \mathrm{dd},{ }^{3} J_{\mathrm{HH}}=9.1 \mathrm{~Hz}\right.$, $\left.{ }^{4} J_{\mathrm{HF}}=4.7 \mathrm{~Hz}, \operatorname{ArH}\right), 7.33(1 \mathrm{H}, \mathrm{dd}, J=7.8,4.8 \mathrm{~Hz}, \operatorname{ArH}), 7.14(1 \mathrm{H}, \mathrm{dt}$, $J=9.2,2.3 \mathrm{~Hz}, \mathrm{ArH}), 4.36\left(2 \mathrm{H}, \mathrm{s}, \mathrm{CH}_{2}\right) .{ }^{13} \mathrm{C} \mathrm{NMR} \delta 190.2(\mathrm{C}=\mathrm{O})$, $157.8\left(\mathrm{~d}, J_{\mathrm{CF}}=233 \mathrm{~Hz}\right.$, indole-C5), $151.1(\operatorname{ArC}), 148.4(\mathrm{ArC}), 137.8$ (ArC), 136.8 (ArC), 135.2 (ArC), $131.4(\operatorname{ArC}), 127.4\left(\mathrm{~d}, J_{\mathrm{CF}}=10 \mathrm{~Hz}\right.$, $\operatorname{ArC}), 124.0$ (ArC), 115.2 (d, $\left.J_{\mathrm{CF}}=27 \mathrm{~Hz}, \operatorname{ArC}\right), 114.7$ (d, $J_{\mathrm{CF}}=10 \mathrm{~Hz}$, $\operatorname{ArC}), 110.3\left(\mathrm{~d}, J_{\mathrm{CF}}=5 \mathrm{~Hz}\right.$, indole-C7a), 107.1 (d, $\left.J_{\mathrm{CF}}=23 \mathrm{~Hz}, \operatorname{ArC}\right)$, 42.1 $\left(\mathrm{CH}_{2}\right) .{ }^{19} \mathrm{~F}$ NMR $\delta$-122.4. Anal. Calcd for $\mathrm{C}_{15} \mathrm{H}_{11} \mathrm{FN}_{2} \mathrm{O}$ : $\mathrm{C}$, 70.86; H, 4.36; N, 11.02. Found: C, 70.61; H, 4.36; N, 10.87.
5.1.3.7. 1-(5-Chloro-1H-indol-2-yl)-2-pyridin-3-yl-ethanone (7g). Prepared from commercial 5-chloro-1H-indole-2-carboxylic acid (355 mg, $1.78 \mathrm{mmol}$ ) and 3-picoline via corresponding acyl chloride $3 g$ (method A). Yellow solid $(137 \mathrm{mg}, 29 \%)$, mp 206$208{ }^{\circ} \mathrm{C}$ (dec). LC-MS $R_{\mathrm{t}} 5.8 \mathrm{~min}(\operatorname{method} 1) ; \mathrm{m} / \mathrm{z}\left[\mathrm{MH}^{+}\right] 271 .{ }^{1} \mathrm{H}$ NMR $\delta 11.97(1 \mathrm{H}$, br s, indole-H1), $8.51(1 \mathrm{H}$, br s, ArH $), 8.43(1 \mathrm{H}$, d, $J=4.8 \mathrm{~Hz}, \operatorname{ArH}), 7.77(1 \mathrm{H}$, br s, $\operatorname{ArH}), 7.70(1 \mathrm{H}, \mathrm{d}, J=7.8 \mathrm{~Hz}$, ArH), $7.52(1 \mathrm{H}$, br s, ArH $), 7.43(1 \mathrm{H}, \mathrm{d}, J=8.7 \mathrm{~Hz}, \operatorname{ArH}), 7.33(1 \mathrm{H}$, dd, $J=7.8,4.8 \mathrm{~Hz}, \operatorname{ArH}), 7.26(1 \mathrm{H}, \mathrm{dd}, J=8.7,1.8 \mathrm{~Hz}, \mathrm{ArH}), 4.38$ $\left(2 \mathrm{H}, \mathrm{s}, \mathrm{CH}_{2}\right) .{ }^{13} \mathrm{C}$ NMR $\delta 190.3(\mathrm{C}=\mathrm{O}), 151.1(\operatorname{ArC}), 148.4(\operatorname{ArC})$, 137.9 (ArC), 136.8 (ArC), $136.6(\operatorname{ArC}), 131.3(\operatorname{ArC}), 128.4(\operatorname{ArC})$, 126.3 (ArC), 125.3 (ArC), 124.0 ( $\mathrm{ArC}), 122.2$ (ArC), 115.0 (ArC), 109.8 (ArC), $42.1\left(\mathrm{CH}_{2}\right)$. Anal. Calcd for $\mathrm{C}_{15} \mathrm{H}_{11} \mathrm{ClN}_{2} \mathrm{O}: \mathrm{C}, 66.55 ; \mathrm{H}$, 4.10; N, 10.35. Found: C, 67.48; H, 4.11; N, 9.99.

5.1.3.8. 1-(5-Bromo-1H-indol-2-yl)-2-pyridin-3-yl-ethanone (7h). Prepared from commercial 5-bromo- $1 H$-indole-2-carboxylic acid (260 mg, $1.08 \mathrm{mmol}$ ) and 3-picoline via corresponding acyl chloride $3 \mathbf{h}$ (method $A$ ). White solid (79 $\mathrm{mg}, 23 \%$ ), decomposes without melting at $224-226{ }^{\circ} \mathrm{C}$. LC-MS $R_{\mathrm{t}} 6.0 \mathrm{~min}$ (method 1 ), $13.3 \mathrm{~min}$ (method 2); $m / z\left[\mathrm{MH}^{+}\right] 315 ; 317 .{ }^{1} \mathrm{H}$ NMR $\delta 11.99(1 \mathrm{H}$, br s, indole-H1), $8.51(1 \mathrm{H}, \mathrm{d}, J=1.8 \mathrm{~Hz}, \mathrm{ArH}), 8.43(1 \mathrm{H}, \mathrm{dd}, J=4.8,1.2 \mathrm{~Hz}$, ArH), $7.92(1 \mathrm{H}$, br s, ArH $), 7.70(1 \mathrm{H}, \mathrm{d}, J=7.8 \mathrm{~Hz}, \operatorname{ArH}), 7.52(1 \mathrm{H}$, d, $J=1.6 \mathrm{~Hz}$, ArH) 7.37 (2H, overlapped, $2 \mathrm{ArH}), 7.33(1 \mathrm{H}, \mathrm{dd}$, $J=7.8,4.8 \mathrm{~Hz}, \mathrm{ArH}), 4.38\left(2 \mathrm{H}, \mathrm{s}, \mathrm{CH}_{2}\right) .{ }^{13} \mathrm{C} \mathrm{NMR} \delta 190.3(\mathrm{C}=\mathrm{O})$, 151.2 (ArC), $148.4(\operatorname{ArC}), 137.9(\operatorname{ArC}), 137.0(\operatorname{ArC}), 136.4(\operatorname{ArC})$, 131.3 (ArC), 129.1 (ArC), 128.7 ( $(\operatorname{ArC}), 125.3$ (ArC), 124.0 ( $\operatorname{ArC})$, 115.4 (ArC), 113.2 ( $\mathrm{ArC}), 109.6(\mathrm{ArC}), 42.1\left(\mathrm{CH}_{2}\right)$. Anal. Calcd for $\mathrm{C}_{15} \mathrm{H}_{11} \mathrm{BrN}_{2} \mathrm{O}$ : C, 57.16; $\mathrm{H}, 3.52 ; \mathrm{N}, 8.89$. Found: $\mathrm{C}, 57.00 ; \mathrm{H}, 3.31$; $\mathrm{N}, 8.40$.

5.1.3.9. 1-(5-Methyl-1H-indol-2-yl)-2-pyridin-3-yl-ethanone (7i). Prepared from commercial 5-methyl-1H-indole-2-carboxylic acid (482 $\mathrm{mg}, 2.75 \mathrm{mmol}$ ) and 3-picoline via corresponding acyl chloride 3i (method A). Yellowish solid $(114 \mathrm{mg}, 17 \%)$, mp 181$182{ }^{\circ} \mathrm{C}$ (dec). LC-MS $R_{\mathrm{t}} 5.7 \mathrm{~min}\left(\operatorname{method} 1\right.$ ); $\mathrm{m} / z\left[\mathrm{MH}^{+}\right] 251 .{ }^{1} \mathrm{H}$ NMR $\delta 11.64(1 \mathrm{H}$, br s, indole-H1), $8.52(1 \mathrm{H}$, br s, ArH $), 8.42(1 \mathrm{H}$, d, $J=3.9 \mathrm{~Hz}, \operatorname{ArH}), 7.70(1 \mathrm{H}, \mathrm{d}, J=7.8 \mathrm{~Hz}, \operatorname{ArH}), 7.46(2 \mathrm{H}$, br $\mathrm{s}$, 2ArH), 7.34-7.29 (2H, m, 2ArH), $7.09(1 \mathrm{H}, \mathrm{d}, J=8.5 \mathrm{~Hz}, \mathrm{ArH}), 4.33$ $\left(2 \mathrm{H}, \mathrm{s}, \mathrm{CH}_{2}\right), 2.34\left(3 \mathrm{H}, \mathrm{s}, \mathrm{CH}_{3}\right) .{ }^{13} \mathrm{C}$ NMR $\delta 190.0(\mathrm{C}=\mathrm{O}), 151.1$ (ArC), 148.3 (ArC), 137.7 (ArC), 137.1 (ArC), 135.4 (ArC), 131.7 (ArC), 129.6 (ArC), 128.2 (ArC), 127.7 (ArC), 123.9 (ArC), 122.3 $(\operatorname{ArC}), 113.0(\mathrm{ArC}), 110.1(\mathrm{ArC}), 42.0\left(\mathrm{CH}_{2}\right), 21.6\left(\mathrm{CH}_{3}\right)$. Anal. Calcd for $\mathrm{C}_{16} \mathrm{H}_{14} \mathrm{~N}_{2} \mathrm{O}$ : C, 76.78; $\mathrm{H}, 5.64 ; \mathrm{N}, 11.19$. Found: $\mathrm{C}, 77.04 ; \mathrm{H}$, $5.52 ; \mathrm{N}, 10.90$

5.1.3.10. 1-(5-Methoxy-1H-indol-2-yl)-2-pyridin-3-yl-ethanone (7j) and 1-(7-methoxy-1H-indol-2-yl)-2-pyridin-3-yl-ethanone $(7 q)^{43}$. Prepared from a $\sim 1: 1$ mixture (method B; $208 \mathrm{mg}$, $0.95 \mathrm{mmol}$ ) of 5-methoxy-1H-indole-2-carboxylic acid ethyl ester (3j) and 7-methoxy-1H-indole-2-carboxylic acid ethyl ester (3q) and 3-picoline. The two final products were separated by chromatography. 7j: (Sundberg 1978) eluted with $\sim 80 \%$ ethyl acetate. Yellowish solid ( $88 \mathrm{mg}, 35 \%$ ). LC-MS $R_{\mathrm{t}} 5.1 \mathrm{~min}$ (method 1), $8.4 \mathrm{~min}$ (method 2); $m / z\left[\mathrm{MH}^{+}\right]$267. ${ }^{1} \mathrm{H}$ NMR $\delta 11.64(1 \mathrm{H}$, br s, indoleH1), $8.52(1 \mathrm{H}, \mathrm{d}, J=2.0 \mathrm{~Hz}, \mathrm{ArH}), 8.43(1 \mathrm{H}, \mathrm{dd}, J=4.7,1.5 \mathrm{~Hz}$, ArH), $7.70(1 \mathrm{H}, \quad \mathrm{dt}, \quad J=7.8, \quad 1.8 \mathrm{~Hz}, \quad \operatorname{ArH}), \quad 7.44(1 \mathrm{H}, \quad \mathrm{d}$, $J=1.8 \mathrm{~Hz}, \mathrm{ArH}), 7.34-7.29(2 \mathrm{H}$, overlapped, $2 \mathrm{ArH}), 7.11(1 \mathrm{H}, \mathrm{d}$, $J=2.4 \mathrm{~Hz}, \operatorname{ArH}), 6.92(1 \mathrm{H}, \mathrm{dd}, J=8.9,2.4 \mathrm{~Hz}, \operatorname{ArH}), 4.33(2 \mathrm{H}, \mathrm{s}$, $\left.\mathrm{CH}_{2}\right), 3.74\left(3 \mathrm{H}, \mathrm{s}, \mathrm{OCH}_{3}\right) .{ }^{13} \mathrm{C}$ NMR $\delta 189.8(\mathrm{C}=\mathrm{O}), 154.6(\operatorname{ArC})$, 147.4 (ArC), 135.6 ( $\operatorname{ArC}), 134.0(\operatorname{ArC}), 132.2(\operatorname{ArC}), 132.1(2 \operatorname{ArC})$, 129.2 (ArC), 127.7 (ArC), 118.0 (ArC), 114.3 (ArC), 110.1 (ArC), 102.8 ( $\mathrm{ArC}), 55.8\left(\mathrm{OCH}_{3}\right), 42.0\left(\mathrm{CH}_{2}\right)$. 7q: eluted with $70 \%$ ethyl acetate. White solid (111 mg, 44\%), mp $171-175{ }^{\circ} \mathrm{C}$ (dec). LC-MS 
$R_{\mathrm{t}} 5.3 \min (\operatorname{method} 1), 8.7 \min (\operatorname{method} 2) ; m / z\left[\mathrm{MH}^{+}\right] 267 .{ }^{1} \mathrm{H}$ NMR $\delta 11.72(1 \mathrm{H}$, br s, indole-H1), $8.51(1 \mathrm{H}, \mathrm{d}, J=1.6 \mathrm{~Hz}, \mathrm{ArH}), 8.42(1 \mathrm{H}$, d, $J=3.4 \mathrm{~Hz}, \operatorname{ArH}), 7.69(1 \mathrm{H}, \mathrm{d}, J=8.0 \mathrm{~Hz}, \operatorname{ArH}), 7.50(1 \mathrm{H}$, d, $J=1.4 \mathrm{~Hz}, \operatorname{ArH}), 7.32(1 \mathrm{H}, \mathrm{dd}, J=7.7,4.7 \mathrm{~Hz}, \operatorname{ArH}), 7.25(1 \mathrm{H}, \mathrm{d}$, $J=8.0 \mathrm{~Hz}, \operatorname{ArH}), 6.99(1 \mathrm{H}, \mathrm{t}, J=7.9 \mathrm{~Hz}, \operatorname{ArH}), 6.79(1 \mathrm{H}, \mathrm{d}$, $J=7.6 \mathrm{~Hz}, \mathrm{ArH}), 4.35\left(2 \mathrm{H}, \mathrm{s}, \mathrm{CH}_{2}\right), 3.87\left(3 \mathrm{H}, \mathrm{s}, \mathrm{OCH}_{3}\right) \cdot{ }^{13} \mathrm{C} \mathrm{NMR} \delta$ $189.7(\mathrm{C}=\mathrm{O}), 151.1(\mathrm{ArC}), 148.3(\operatorname{ArC}), 147.4(\operatorname{ArC}), 137.8(\operatorname{ArC})$, 135.6 (ArC), $131.6(\operatorname{ArC}), 129.5(\operatorname{ArC}), 128.8(\operatorname{ArC}), 123.9(\operatorname{ArC})$, 121.6 (ArC), 115.3 (ArC), $111.0(\operatorname{ArC}), 105.6(\operatorname{ArC}), 55.9\left(\mathrm{OCH}_{3}\right)$, $42.2\left(\mathrm{CH}_{2}\right)$. Anal. Calcd for $\mathrm{C}_{16} \mathrm{H}_{14} \mathrm{~N}_{2} \mathrm{O}_{2}: \mathrm{C}, 72.16 ; \mathrm{H}, 5.30 ; \mathrm{N}$, 10.52. Found: C, 72.90; H, 5.14; N, 10.20 .

5.1.3.11. 1-(5-Nitro-1H-indol-2-yl)-2-pyridin-3-yl-ethanone (7k). Prepared from commercial 5-nitro- $1 H$-indole-2-carboxylic acid ethyl ester 3k (249 mg, $1.01 \mathrm{mmol})$ and 3-picoline. Reaction time: $48 \mathrm{~h}$. Bright yellow solid (42 mg, 15\%). LC-MS $R_{\mathrm{t}} 5.3 \mathrm{~min}$ (method 1); $m / z\left[\mathrm{MH}^{+}\right] 282 .{ }^{1} \mathrm{H}$ NMR $\delta 12.46(1 \mathrm{H}$, br s, indole-H1), 8.75 $(1 \mathrm{H}$, br s, ArH $), 8.52(1 \mathrm{H}$, br s, $\operatorname{ArH}), 8.44(1 \mathrm{H}, \mathrm{d}, J=4.6 \mathrm{~Hz}, \operatorname{ArH})$, $8.12(1 \mathrm{H}, \mathrm{d}, J=9.2 \mathrm{~Hz}, \operatorname{ArH}), 7.82(1 \mathrm{H}, \mathrm{s}, \operatorname{ArH}), 7.71(1 \mathrm{H}, \mathrm{d}$, $J=7.8 \mathrm{~Hz}, \mathrm{ArH}), 7.57(1 \mathrm{H}, \mathrm{d}, J=9.2 \mathrm{~Hz}, \mathrm{ArH}), 7.34(1 \mathrm{H}, \mathrm{dd}, J=8.0$, $5.0 \mathrm{~Hz}, \mathrm{ArH}), 4.44\left(2 \mathrm{H}, \mathrm{s}, \mathrm{CH}_{2}\right)$.

5.1.3.12. 1-(5-Phenyl-1H-indol-2-yl)-2-pyridin-3-ylethanone (71) ${ }^{\mathbf{4 6}}$. Prepared according to a literature procedure. A suspension of tetrakis(triphenylphosphine)palladium $(0)(7 \mathrm{mg}, 6 \mu \mathrm{mol})$ in a mixture of $1 \mathrm{M}$ potassium carbonate $(0.8 \mathrm{~mL})$, ethanol $(0.8 \mathrm{~mL})$ and toluene $(0.8 \mathrm{~mL})$ was added to a stirred suspension of bromoindole $\mathbf{7 h}$ (38 mg, $0.12 \mathrm{mmol}$ ) and phenylboronic acid (33 $\mathrm{mg}, 0.26 \mathrm{mmol}$ ) in a 1:1 mixture of toluene and ethanol $(0.8 \mathrm{~mL})$. The (initially ochre colored) suspension was heated at reflux temperature for $20 \mathrm{~h}$, allowed to cool down to room temperature and diluted with ethyl acetate. Evaporation with silica and chromatographic purification afforded the title product as a bright yellow solid (12 mg, 32\%). LCMS $R_{\mathrm{t}} 6.5 \mathrm{~min}(\operatorname{method} 1), 10.2 \mathrm{~min}(\operatorname{method} 2) ; \mathrm{m} / z\left[\mathrm{MH}^{+}\right] 313 .{ }^{1} \mathrm{H}$ NMR $\delta 11.85(1 \mathrm{H}$, br s, indole-H1 ), $8.54(1 \mathrm{H}, \mathrm{d}, J=1.8 \mathrm{~Hz}, \mathrm{ArH}), 8.44$ $(1 \mathrm{H}, \mathrm{dd}, J=4.8,1.6 \mathrm{~Hz}, \operatorname{ArH}), 7.96(1 \mathrm{H}, \mathrm{br} \mathrm{s}, \operatorname{ArH}), 7.72(1 \mathrm{H}, \mathrm{dt}$, $J=7.8,1.8 \mathrm{~Hz}, \mathrm{ArH}), 7.67-7.49$ (5H, overlapped, $5 \mathrm{ArH}), 7.43(2 \mathrm{H}, \mathrm{t}$, $J=7.7 \mathrm{~Hz}, 2 \mathrm{ArH}), 7.33(1 \mathrm{H}, \mathrm{dd}, J=8.0,2.7 \mathrm{~Hz}, \operatorname{ArH}), 7.29(1 \mathrm{H}, \mathrm{t}$, $J=7.2 \mathrm{~Hz}, \mathrm{ArH}), 4.39\left(2 \mathrm{H}, \mathrm{s}, \mathrm{CH}_{2}\right) .{ }^{13} \mathrm{C}$ NMR $\delta 190.1(\mathrm{C}=\mathrm{O}), 151.1$ (ArC), 148.3 (ArC), 141.6 (ArC), 138.1 (ArC), 137.8 (ArC), 136.1 (ArC), 134.6 (ArC), 132.1 (ArC), 132.0 (ArC), 129.42 (2 ArC), 129.36 (ArC), 127.3 (2 ArC), 125.9 (ArC), 124.0 (ArC), 121.0 (ArC), 113.8 (ArC), 111.0 (ArC), $42.1\left(\mathrm{CH}_{2}\right)$. Anal. Calcd for $\mathrm{C}_{21} \mathrm{H}_{16} \mathrm{~N}_{2} \mathrm{O}: \mathrm{C}, 80.75$; H, 5.16; N, 8.97. Found: C, 80.01; H, 5.23; N, 8.49.

5.1.3.13. 2-Pyridin-3-yl-1-(5-trifluoromethoxy-1H-indol-2-yl)ethanone $(7 \mathrm{~m})$. Prepared from commercial 5-trifluoromethoxy$1 \mathrm{H}$-indole-2-carboxylic acid (256 mg, $1.01 \mathrm{mmol}$ ) and 3-picoline via corresponding acyl chloride $\mathbf{3 m}$ (method A). Yellowish solid (90 mg, 28\%), mp $184-186{ }^{\circ} \mathrm{C}$. LC-MS $R_{\mathrm{t}} 6.2 \mathrm{~min}$ (method 1 ); $\mathrm{m} / \mathrm{z}$ $\left[\mathrm{MH}^{+}\right]$321. ${ }^{1} \mathrm{H}$ NMR $\delta 12.04(1 \mathrm{H}$, br s, indole-H1), $8.52(1 \mathrm{H}, \mathrm{d}$, $J=1.6 \mathrm{~Hz}, \operatorname{ArH}), 8.43(1 \mathrm{H}, \mathrm{dd}, J=4.6,1.4 \mathrm{~Hz}, \operatorname{ArH}), 7.71-7.69(2 \mathrm{H}$, overlapped, $2 \mathrm{ArH}), 7.60(1 \mathrm{H}$, br s, $\operatorname{ArH}), 7.50(1 \mathrm{H}, \mathrm{d}, J=8.9 \mathrm{~Hz}$, ArH), $7.33(1 \mathrm{H}, \mathrm{dd}, J=7.8,4.8 \mathrm{~Hz}, \operatorname{ArH}), 7.24(1 \mathrm{H}, \mathrm{d}, J=8.9 \mathrm{~Hz}$, $\mathrm{ArH}), 4.38\left(2 \mathrm{H}, \mathrm{s}, \mathrm{CH}_{2}\right) .{ }^{13} \mathrm{C}$ NMR $\delta 190.3(\mathrm{C}=\mathrm{O}), 151.1(\mathrm{ArC})$, 148.4 (ArC), 142.9 (ArC), 137.8 (ArC), 137.1 (ArC), 136.8 (ArC), 131.3 (ArC), 127.3 (ArC), 124.0 (ArC), 120.9 (d, $J_{\mathrm{CF}}=254 \mathrm{~Hz}$, $\mathrm{OCF}_{3}$ ), 120.1 ( $\left.\mathrm{ArC}\right), 115.2$ (ArC), 114.8 (ArC), 110.6 ( $\left.\mathrm{ArC}\right), 42.1$ $\left(\mathrm{CH}_{2}\right) .{ }^{19} \mathrm{~F}$ NMR $\delta$-56.9. Anal. Calcd for $\mathrm{C}_{16} \mathrm{H}_{11} \mathrm{~F}_{3} \mathrm{~N}_{2} \mathrm{O}_{2}$ : C, 60.00; H, 3.46; N, 8.75. Found: C, 59.95; H, 3.43; N, 8.45.

5.1.3.14. 1-(5-Benzyloxy-1H-indol-2-yl)-2-pyridin-3-yl-ethanone (7n). Prepared from commercial 5-benzyloxy-1H-indole-2-carboxylic acid ethyl ester $3 \mathrm{n}$ (499 $\mathrm{mg}, 1.69 \mathrm{mmol}$ ) and 3-picoline. Off-white solid (166 mg, 29\%), mp $183-184^{\circ} \mathrm{C}$. LC-MS $R_{\mathrm{t}} 6.5 \mathrm{~min}$ (method 1), $14.8 \mathrm{~min}(\operatorname{method} 2) ; \mathrm{m} / z\left[\mathrm{MH}^{+}\right] 343 .{ }^{1} \mathrm{H}$ NMR $\delta$ $11.65(1 \mathrm{H}$, br s, indole-H1), $8.52(1 \mathrm{H}$, br s, $\operatorname{ArH}), 8.42(1 \mathrm{H}, \mathrm{d}$, $J=4.8 \mathrm{~Hz}, \operatorname{ArH}), 7.70(1 \mathrm{H}, \mathrm{d}, J=7.8 \mathrm{~Hz}, \mathrm{ArH}), 7.45-7.43$ (3H, overlapped, 3ArH), 7.38-7.27 (5H, overlapped, 5ArH), $7.21(1 \mathrm{H}, \mathrm{d}$, $J=1.8 \mathrm{~Hz}, \operatorname{ArH}), 7.00(1 \mathrm{H}, \mathrm{dd}, J=8.9,2.3 \mathrm{~Hz}, \operatorname{ArH}), 5.08(2 \mathrm{H}, \mathrm{s}$, benzyl CH$\left.{ }_{2}\right), 4.32\left(2 \mathrm{H}, \mathrm{s}, \mathrm{C}(\mathrm{O}) \mathrm{CH}_{2}\right) .{ }^{13} \mathrm{C}$ NMR $\delta 189.9(\mathrm{C}=\mathrm{O}), 153.5(\mathrm{ArC})$, 151.1 (ArC), 148.3 (ArC), $137.9(\operatorname{ArC}), 137.7(\operatorname{ArC}), 135.8(\operatorname{ArC})$, 134.1 (ArC), 131.7 (ArC), 128.9 (2C, 2 phenyl C), 128.3 (ArC), 128.2 (2C, 2 phenyl C), 127.7 (ArC), 124.0 (ArC), 118.5 (ArC), 114.3 (ArC), $110.2(\operatorname{ArC}), 104.4(\mathrm{ArC}), 70.1$ (benzyl $\mathrm{CH}_{2}$ ), $42.0\left(\mathrm{C}(\mathrm{O}) \mathrm{CH}_{2}\right)$. Anal. Calcd for $\mathrm{C}_{22} \mathrm{H}_{18} \mathrm{~N}_{2} \mathrm{O}_{2}$ : C, 77.17; $\mathrm{H}, 5.30 ; \mathrm{N}$, 8.18. Found: C, 76.95; H, 5.01; N, 8.10.

\subsubsection{1-(5-Hydroxy-1H-indol-2-yl)-2-pyridin-3-yl-ethanone (7o) and 2-(1-hydroxy-2-pyridin-3-ylethyl)-1H-indol-5-ol} (17). Ammonium formate ( $485 \mathrm{mg}, 7.50 \mathrm{mmol}$ ) and Pd black (surface area $40-60 \mathrm{~m}^{2} / \mathrm{g}, 110 \mathrm{mg}, 1.03 \mathrm{mmol}$ ) were added to a stirred suspension of benzyl ether $\mathbf{7 n}(166 \mathrm{mg}, 0.13 \mathrm{mmol})$ in dry methanol $(55 \mathrm{~mL})$. The blue-greenish suspension was stirred at room temperature for $1 \mathrm{~h}$ and filtered through Celite 545. The filter was extensively washed with methanol and the combined filtrate and washings were concentrated under reduced pressure. Chromatographic purification yielded hydroxyindole 7o (eluted with 95\% ethyl acetate; $38 \mathrm{mg}, 31 \%$ ) and byproduct 17 (eluted with $100 \%$ ethyl acetate; $69 \mathrm{mg}, 56 \%)$. Shortening the reaction time to 30 min afforded 70 as the only product in a 58\% yield. Analytical data: 7o, yellow solid which decomposes without melting above $200{ }^{\circ} \mathrm{C}$. LC-MS $R_{\mathrm{t}} 4.1 \mathrm{~min}(\operatorname{method} 1) ; m / z\left[\mathrm{MH}^{+}\right] 253 .{ }^{1} \mathrm{H}$ NMR $\delta$ $11.49(1 \mathrm{H}$, br s, indole-H1), $8.97(1 \mathrm{H}, \mathrm{s}, \mathrm{OH}), 8.51(1 \mathrm{H}, \mathrm{br} \mathrm{s}, \mathrm{ArH})$, $8.42(1 \mathrm{H}, \mathrm{d}, J=3.6 \mathrm{~Hz}, \quad \operatorname{ArH}), 7.69\left(1 \mathrm{H}, \mathrm{dt},{ }^{3} J_{\mathrm{HH}}=7.8 \mathrm{~Hz}\right.$, $\left.{ }^{4} J_{\mathrm{HH}}=1.8 \mathrm{~Hz}, \operatorname{ArH}\right), 7.36(1 \mathrm{H}, \mathrm{d}, J=1.8 \mathrm{~Hz}, \operatorname{ArH}), 7.32(1 \mathrm{H}, \mathrm{dd}$, $J=7.8,4.8 \mathrm{~Hz}, \operatorname{ArH}), 7.22(1 \mathrm{H}, \mathrm{d}, J=8.9 \mathrm{~Hz}, \operatorname{ArH}), 6.93(1 \mathrm{H}, \mathrm{d}$, $J=2.3 \mathrm{~Hz}, \operatorname{ArH}), 6.81(1 \mathrm{H}, \mathrm{dd}, J=8.7,2.3 \mathrm{~Hz}, \operatorname{ArH}), 4.29(2 \mathrm{H}, \mathrm{s}$, $\left.\mathrm{CH}_{2}\right) .{ }^{13} \mathrm{C}$ NMR $\delta 189.8(\mathrm{C}=\mathrm{O}), 152.0(\mathrm{ArC}), 151.1(\mathrm{ArC}), 148.3$ (ArC), 137.7 (ArC), 135.6 (ArC), 133.5 (ArC), 131.7 (ArC), 128.1 (ArC), 123.9 (ArC), 118.0 (ArC), 113.9 (ArC), 109.6 (ArC), 105.3 (ArC), $41.9\left(\mathrm{CH}_{2}\right)$. Compound 17, yellowish solid, mp $188-190{ }^{\circ} \mathrm{C}$. LC-MS $R_{\mathrm{t}} 3.1 \mathrm{~min}$ (method 1 ); $\mathrm{m} / z\left[\mathrm{MH}^{+}\right] 255 .{ }^{1} \mathrm{H}$ NMR $\delta 10.68$ $(1 \mathrm{H}$, br s, indole-H1), $8.50(1 \mathrm{H}$, br s, ArH), 8.33-8.32 (2H, overlapped, $\mathrm{ArH}, \mathrm{OH}$ on indole), $7.55\left(1 \mathrm{H}, \mathrm{dd},{ }^{3} \mathrm{~J}_{\mathrm{HH}}=7.8 \mathrm{~Hz}\right.$, $\left.{ }^{4} J_{\mathrm{HH}}=1.8 \mathrm{~Hz}, \operatorname{ArH}\right), 7.22(1 \mathrm{H}, \mathrm{dd}, J=7.8,4.8 \mathrm{~Hz}, \operatorname{ArH}), 7.08(1 \mathrm{H}, \mathrm{d}$, $J=8.6 \mathrm{~Hz}, \operatorname{ArH}), 6.70(1 \mathrm{H}, \mathrm{d}, J=2.0 \mathrm{~Hz}, \operatorname{ArH}), 6.50(1 \mathrm{H}, \mathrm{dd}$, $\left.{ }^{3} J_{\mathrm{HH}}=8.6 \mathrm{~Hz},{ }^{4} J_{\mathrm{HH}}=2.3 \mathrm{~Hz}, \operatorname{ArH}\right), 6.01(1 \mathrm{H}, \mathrm{d}, J=1.4 \mathrm{~Hz}, \operatorname{ArH}), 5.44$ $(1 \mathrm{H}, \mathrm{d}, J=5.3 \mathrm{~Hz}, \mathrm{CHOH}), 4.81(1 \mathrm{H}, \mathrm{m}, \mathrm{CHOH}), 3.07(1 \mathrm{H}, \mathrm{dd}$, $\left.{ }^{2} J_{\mathrm{HH}}=13.6 \mathrm{~Hz},{ }^{3} J_{\mathrm{HH}}=5.4 \mathrm{~Hz}, \mathrm{CH}_{2}\right), 2.97\left(1 \mathrm{H}, \mathrm{dd},{ }^{2} J_{\mathrm{HH}}=13.6 \mathrm{~Hz}\right.$, $\left.{ }^{3} J_{\mathrm{HH}}=8.0 \mathrm{~Hz}, \mathrm{CH}_{2}\right) .{ }^{13} \mathrm{C}$ NMR $\delta 151.0(\mathrm{ArC}), 150.9(\mathrm{ArC}), 147.7$ (ArC), 143.4 (ArC), 137.3 (ArC), 134.9 (ArC), 131.0 (ArC), 128.9 (ArC), 123.6 (ArC), 111.9 (ArC), 111.2 (ArC), $104.2(\operatorname{ArC}), 97.7$ ( $\mathrm{ArC}), 68.4(\mathrm{CHOH}), 41.0\left(\mathrm{CH}_{2}\right)$.

5.1.3.16. 1-(6-Fluoro-1H-indol-2-yl)-2-pyridin-3-yl-ethanone (7p). Prepared from 6-fluoro- $1 \mathrm{H}$-indole-2-carboxylic acid ethyl ester 3p (method B; $80 \mathrm{mg}, 0.39 \mathrm{mmol}$ ) and 3-picoline. Bright yellow solid (59 mg, 60\%), mp $192-193{ }^{\circ} \mathrm{C}(\mathrm{dec})$. LC-MS $R_{\mathrm{t}} 5.4 \mathrm{~min}$ $(\operatorname{method} 1) ; m / z\left[\mathrm{MH}^{+}\right] 255 .{ }^{1} \mathrm{H}$ NMR $\delta 11.86(1 \mathrm{H}$, br s, indole$\mathrm{H} 1), 8.52(1 \mathrm{H}, \mathrm{d}, J=1.7 \mathrm{~Hz}, \mathrm{ArH}), 8.43(1 \mathrm{H}, \mathrm{dd}, J=4.9,1.7 \mathrm{~Hz}$, $\operatorname{ArH}), 7.74(1 \mathrm{H}$, dd, overlapped, $\operatorname{ArH}), 7.71(1 \mathrm{H}, \mathrm{d}$, overlapped, $\operatorname{ArH}), 7.60(1 \mathrm{H}, \mathrm{d}, J=1.4 \mathrm{~Hz}, \operatorname{ArH}), 7.33(1 \mathrm{H}, \mathrm{dd}, J=7.7,4.9 \mathrm{~Hz}$, ArH $), 7.11\left(1 \mathrm{H}, \mathrm{dd},{ }^{3} J_{\mathrm{HF}}=9.9 \mathrm{~Hz},{ }^{4} J_{\mathrm{HH}}=1.9 \mathrm{~Hz}, \operatorname{ArH}\right), 6.95(1 \mathrm{H}, \mathrm{dt}$, $\left.{ }^{3} J=9.3 \mathrm{~Hz},{ }^{4} J=1.9 \mathrm{~Hz}, \operatorname{ArH}\right), 4.34\left(2 \mathrm{H}, \mathrm{s}, \mathrm{CH}_{2}\right) .{ }^{13} \mathrm{C}$ NMR $\delta 189.8$ $(\mathrm{C}=0), 161.6\left(\mathrm{~d}, J_{\mathrm{CF}}=219 \mathrm{~Hz}\right.$, indole-C6), $151.1(\operatorname{ArC}), 148.4(\operatorname{ArC})$, $138.6\left(\mathrm{~d}, J_{\mathrm{CF}}=13 \mathrm{~Hz}, \mathrm{ArC}\right), 137.8(\mathrm{ArC}), 136.3$ (d, $J_{\mathrm{CF}}=3 \mathrm{~Hz}$, indoleC3a), 131.5 (ArC), 125.1 (d, $\left.J_{\mathrm{CF}}=11 \mathrm{~Hz}, \operatorname{ArC}\right), 124.4(\operatorname{ArC}), 124.0$ (ArC), 110.9 (ArC), $110.4\left(\mathrm{~d}, J_{\mathrm{CF}}=26 \mathrm{~Hz}, \operatorname{ArC}\right), 98.6\left(\mathrm{~d}, J_{\mathrm{CF}}=26 \mathrm{~Hz}\right.$, $\mathrm{ArC}), 41.9\left(\mathrm{CH}_{2}\right) .{ }^{19} \mathrm{~F}$ NMR $\delta-115.0$. Anal. Calcd for $\mathrm{C}_{15} \mathrm{H}_{11} \mathrm{FN}_{2} \mathrm{O}$ : C, 70.86; H, 4.36; N, 11.02. Found: C, 71.12; H, 4.72; N, 10.81 . 
5.1.3.17. 1-(4-Benzyloxy-5-methoxy-1H-indol-2-yl)-2-pyridin-3yl-ethanone (7r). Prepared from 4-benzyloxy-5-methoxy-1H-indole-2-carboxylic acid ethyl ester 3r (method B; $282 \mathrm{mg}$, $0.87 \mathrm{mmol}$ ) and 3-picoline. Yellow solid (84 mg, 26\%), mp 137$139{ }^{\circ} \mathrm{C}$. LC-MS $R_{\mathrm{t}} 6.3 \mathrm{~min}(\operatorname{method} 1), 15.7 \mathrm{~min}(\operatorname{method} 2) ; \mathrm{m} / \mathrm{z}$ $\left[\mathrm{MH}^{+}\right]$373. ${ }^{1} \mathrm{H}$ NMR $\delta 11.65(1 \mathrm{H}$, br s, indole-H1), $8.51(1 \mathrm{H}, \mathrm{br} \mathrm{s}$, $\operatorname{ArH}), 8.43(1 \mathrm{H}, \mathrm{d}, J=4.1 \mathrm{~Hz}, \operatorname{ArH}), 7.69(1 \mathrm{H}, \mathrm{d}, J=7.8 \mathrm{~Hz}, \operatorname{ArH})$, 7.54-7.50 (3H, overlapped, 3ArH), 7.38-7.30 (4H, overlapped, $4 \operatorname{ArH}), 7.14(1 \mathrm{H}, \mathrm{d}, J=8.8 \mathrm{~Hz}, \operatorname{ArH}), 7.07(1 \mathrm{H}, \mathrm{d}, J=8.8 \mathrm{~Hz}, \operatorname{ArH})$, $5.22\left(2 \mathrm{H}, \mathrm{s}\right.$, benzyl $\left.\mathrm{CH}_{2}\right), 4.36\left(2 \mathrm{H}, \mathrm{s}, \mathrm{C}(\mathrm{O}) \mathrm{CH}_{2}\right), 3.79\left(3 \mathrm{H} \mathrm{s}, \mathrm{OCH}_{3}\right)$. ${ }^{13} \mathrm{C}$ NMR $\delta 190.0(\mathrm{C}=\mathrm{O}), 151.1(\mathrm{ArC}), 148.3(\mathrm{ArC}), 144.8(\mathrm{ArC})$ 141.5 (ArC), 138.4 (ArC), 137.8 (ArC), 135.6 (ArC), 131.6 (ArC), 128.8 (2 ArC), 128.6 (2 ArC), 128.4 (ArC), 124.0 (ArC), 122.9 (ArC), $117.4(\mathrm{ArC}), 108.4(\mathrm{ArC}), 107.8$ (ArC), 74.6 (benzyl $\mathrm{CH}_{2}$ ), $58.5\left(\mathrm{OCH}_{3}\right), 41.9\left(\mathrm{C}(\mathrm{O}) \mathrm{CH}_{2}\right)$. Anal. Calcd for $\mathrm{C}_{23} \mathrm{H}_{20} \mathrm{~N}_{2} \mathrm{O}_{3}: \mathrm{C}$, 74.18; H, 5.41; N, 7.52. Found: C, 74.98; H, 5.29; N, 7.42.

5.1.3.18. 1-(4-Hydroxy-5-methoxy-1H-indol-2-yl)-2-pyridin-3yl-ethanone (7s). Benzyl ester $7 \mathbf{r}(59 \mathrm{mg}, 0.16 \mathrm{mmol})$ was dissolved in absolute ethanol $(15 \mathrm{~mL})$ to give a clear yellow solution to which $3 \%$ Pd on activated carbon $(60 \mathrm{mg}, 17 \mu \mathrm{mol})$ was added. The flask was evacuated and back-filled with hydrogen gas (repeated three times). The suspension was stirred at room temperature for $45 \mathrm{~min}$ (until TLC indicated reaction completion) and filtered through Celite 545. The filter was extensively washed with ethyl acetate and the combined filtrate and washings were concentrated under reduced pressure. Chromatographic purification (the title product eluted with $80-90 \%$ ethyl acetate) afforded the title hydroxyindole $7 \mathrm{~s}$ as a light brown half-solid in a $53 \%$ (24 mg) yield. LC-MS $R_{\mathrm{t}} 4.3 \mathrm{~min}$ (method 1 ); $\mathrm{m} / z\left[\mathrm{MH}^{+}\right] 283 .{ }^{1} \mathrm{H}$ NMR $\delta 11.47(1 \mathrm{H}$, br s, indole-H1), $9.26(1 \mathrm{H}, \mathrm{s}, \mathrm{OH}), 8.52(1 \mathrm{H}, \mathrm{br} \mathrm{s}, \mathrm{ArH}), 8.42(1 \mathrm{H}, \mathrm{d}$, $J=3.9 \mathrm{~Hz}, \operatorname{ArH}), 7.70(1 \mathrm{H}, \mathrm{d}, J=7.6 \mathrm{~Hz}, \operatorname{ArH}), 7.54(1 \mathrm{H}, \mathrm{d}, J=1.4 \mathrm{~Hz}$, ArH), $7.33(1 \mathrm{H}, \mathrm{dd}, J=7.8,4.8 \mathrm{~Hz}, \mathrm{ArH}), 7.04(1 \mathrm{H}, \mathrm{d}, J=8.7 \mathrm{~Hz}, \mathrm{ArH})$, $6.78(1 \mathrm{H}, \mathrm{d}, J=8.7 \mathrm{~Hz}, \mathrm{ArH}), 4.31\left(2 \mathrm{H}, \mathrm{s}, \mathrm{CH}_{2}\right), 3.72\left(3 \mathrm{H} \mathrm{s}, \mathrm{OCH}_{3}\right) .{ }^{13} \mathrm{C}$ NMR $\delta 189.6$ (C=O), 151.1 ( $\operatorname{ArC}), 148.3$ (ArC), 141.2 (ArC), 139.5 (ArC), 137.7 (ArC), 136.0 (ArC), 134.9 (ArC), 131.8 (ArC), 124.0 (ArC), 119.8 (ArC), $117.8(\operatorname{ArC}), 108.4(\operatorname{ArC}), 103.4(\operatorname{ArC}), 59.0$ $\left(\mathrm{OCH}_{3}\right), 41.9\left(\mathrm{CH}_{2}\right)$.

5.1.3.19. 1-(4,6-Dichloro-1H-indol-2-yl)-2-pyridin-3-yl-ethanone (7t). Prepared from commercial 4,6-dichloro- $1 \mathrm{H}$-indole-2-carbonyl chloride 3t $(647 \mathrm{mg}, 2.47 \mathrm{mmol})$ and 3-picoline. Off-white solid (198 mg, 26\%), mp 223-225 ${ }^{\circ} \mathrm{C}$. LC-MS $R_{\mathrm{t}} 6.5 \mathrm{~min}$ (method 1 ); $\mathrm{m} / \mathrm{z}$ $\left[\mathrm{MH}^{+}\right]$305. ${ }^{1} \mathrm{H}$ NMR $\delta 12.26(1 \mathrm{H}$, br s, indole-H1), $8.52(1 \mathrm{H}, \mathrm{d}$, $J=1.7 \mathrm{~Hz}, \operatorname{ArH}), 8.44(1 \mathrm{H}, \mathrm{dd}, J=4.8,1.7 \mathrm{~Hz}, \operatorname{ArH}), 7.70(1 \mathrm{H}, \mathrm{dt}$, $J=7.8,1.7 \mathrm{~Hz}, \operatorname{ArH}), 7.62(1 \mathrm{H}, \mathrm{br} \mathrm{s}, \operatorname{ArH}), 7.41(1 \mathrm{H}, \mathrm{dd}, J=1.6,0.9 \mathrm{~Hz}$, $\operatorname{ArH}), 7.33(1 \mathrm{H}, \mathrm{dd}, J=7.8,4.8 \mathrm{~Hz}, \mathrm{ArH}), 7.27(1 \mathrm{H}, \mathrm{d}, J=1.8 \mathrm{~Hz}, \mathrm{ArH})$, $4.44\left(2 \mathrm{H}, \mathrm{s}, \mathrm{CH}_{2}\right) .{ }^{13} \mathrm{C}$ NMR $\delta 190.3(\mathrm{C}=\mathrm{O}), 151.2(\operatorname{ArC}), 148.4(\operatorname{ArC})$, 138.7 (ArC), 137.9 (ArC), 136.8 (ArC), 131.2 (ArC), 130.4 (ArC), 128.2 ( $\mathrm{ArC}$ ), 125.2 ( $\mathrm{ArC}), 124.0(\mathrm{ArC}), 120.7$ ( $\mathrm{ArC}), 112.0(\mathrm{ArC}), 108.1$ (ArC), $42.0\left(\mathrm{CH}_{2}\right)$. Anal. Calcd for $\mathrm{C}_{15} \mathrm{H}_{10} \mathrm{Cl}_{2} \mathrm{~N}_{2} \mathrm{O}: \mathrm{C}, 59.04 ; \mathrm{H}, 3.30 ; \mathrm{N}$, 9.18. Found: C, 59.79; H, 3.26; N, 9.21.

5.1.3.20. 1-(4,6-Dimethoxy-1H-indol-2-yl)-2-pyridin-3-yl-ethanone (7u). Prepared from commercial 4,6-dimethoxy-1H-indole2-carboxylic acid methyl ester $3 \mathbf{u}(241 \mathrm{mg}, 1.01 \mathrm{mmol})$ and 3-picoline. Off-white solid ( $240 \mathrm{mg}, 80 \%$ ), mp 195-197 ${ }^{\circ} \mathrm{C}$. LC-MS $R_{\mathrm{t}}$ $5.3 \mathrm{~min}$ (method 1); $\mathrm{m} / z\left[\mathrm{MH}^{+}\right] 297 .{ }^{1} \mathrm{H}$ NMR $\delta 11.60(1 \mathrm{H}, \mathrm{s}$, indole-H1), $8.52(1 \mathrm{H}, \mathrm{d}, J=1.6 \mathrm{~Hz}, \mathrm{ArH}), 8.41(1 \mathrm{H}, \mathrm{dd}, J=4.8,1.6 \mathrm{~Hz}$, ArH $), \quad 7.69(1 \mathrm{H}, \quad \mathrm{dt}, \quad J=7.8, \quad 0.9 \mathrm{~Hz}, \quad \operatorname{ArH}), \quad 7.51(1 \mathrm{H}, \quad \mathrm{d}$, $J=1.8 \mathrm{~Hz}, \operatorname{ArH}), 7.31(1 \mathrm{H}, \mathrm{dd}, J=7.8,4.8 \mathrm{~Hz}, \operatorname{ArH}), 6.40(1 \mathrm{H}, \mathrm{d}$, $J=1.5 \mathrm{~Hz}, \mathrm{ArH}), 6.17(1 \mathrm{H}, \mathrm{d}, J=1.5 \mathrm{~Hz}, \mathrm{ArH}), 4.25\left(2 \mathrm{H}, \mathrm{s}, \mathrm{CH}_{2}\right)$, $3.84\left(3 \mathrm{H}, \mathrm{s}, \mathrm{OCH}_{3}\right), 3.73\left(3 \mathrm{H}, \mathrm{s}, \mathrm{OCH}_{3}\right) .{ }^{13} \mathrm{C} \mathrm{NMR} \delta 188.6(\mathrm{C}=\mathrm{O})$, 160.8 (ArC), 155.4 (ArC), 151.0 (ArC), 148.2 (ArC), 140.6 ( $\operatorname{ArC}$ ), 137.6 ( $\mathrm{ArC}), 133.5(\mathrm{ArC}), 132.0(\mathrm{ArC}), 123.9(\mathrm{ArC}), 113.8(\mathrm{ArC})$ $109.2(\mathrm{ArC}), 93.1(\mathrm{ArC}), 87.0(\mathrm{ArC}), 55.83\left(\mathrm{OCH}_{3}\right), 55.76\left(\mathrm{OCH}_{3}\right)$,
41.5 $\left(\mathrm{CH}_{2}\right)$. Anal. Calcd for $\mathrm{C}_{17} \mathrm{H}_{16} \mathrm{~N}_{2} \mathrm{O}_{3}: \mathrm{C}, 68.91 ; \mathrm{H}, 5.44 ; \mathrm{N}, 9.45$. Found: C, 69.65; H, 5.17; N, 9.40.

5.1.3.21. 1-(1H-Indol-2-yl)-2-pyridin-3-yl-propan-1-one (7v). Prepared from commercial $1 H$-indole-2-carboxylic acid ethyl ester 3a (983 $\mathrm{mg}, 5.04 \mathrm{mmol}$ ) and 3-ethylpyridine. Yellow half-solid (220 mg, 17\%). LC-MS $R_{\mathrm{t}} 5.7 \mathrm{~min}$ (method 1), 7.3 min (method 2); $m / z\left[\mathrm{MH}^{+}\right] 251 .{ }^{1} \mathrm{H}$ NMR $\delta 11.74(1 \mathrm{H}$, br s, indole-H1), 8.65 $(1 \mathrm{H}, \mathrm{d}, J=1.7 \mathrm{~Hz}, \operatorname{ArH}), 8.39(1 \mathrm{H}, \mathrm{dd}, J=4.8,1.7 \mathrm{~Hz}, \operatorname{ArH}), 7.75$ $(1 \mathrm{H}, \mathrm{dt}, J=7.8,1.7 \mathrm{~Hz}, \operatorname{ArH}), 7.64(1 \mathrm{H}, \mathrm{d}, J=8.2 \mathrm{~Hz}, \mathrm{ArH}), 7.53$ $(1 \mathrm{H}, \mathrm{d}, J=1.4 \mathrm{~Hz}, \operatorname{ArH}), 7.37(1 \mathrm{H}, \mathrm{d}, J=8.5 \mathrm{~Hz}, \operatorname{ArH}), 7.31(1 \mathrm{H}, \mathrm{dd}$, $J=7.9,4.7 \mathrm{~Hz}, \operatorname{ArH}), 7.23(1 \mathrm{H}, \mathrm{t}, J=7.7 \mathrm{~Hz}, \operatorname{ArH}), 7.03(1 \mathrm{H}, \mathrm{t}$, $J=7.4 \mathrm{~Hz}, \mathrm{ArH}), 4.89\left(1 \mathrm{H}, \mathrm{q}, J=7.0 \mathrm{~Hz}, \mathrm{CHCH}_{3}\right), 1.46(3 \mathrm{H}, \mathrm{d}$, $\left.J=7.0 \mathrm{~Hz}, \mathrm{CH}_{3}\right) .{ }^{13} \mathrm{C}$ NMR $\delta 193.0(\mathrm{C}=\mathrm{O}), 149.7(\operatorname{ArC}), 148.6(\operatorname{ArC})$, 138.6 (ArC), 137.7 (ArC), 135.5 (ArC), 134.7 (ArC), 127.3 (ArC), 126.3 (ArC), 124.3 (ArC), 123.3 (ArC), 120.9 (ArC), 113.3 (ArC), 110.7 ( $\mathrm{ArC}), 44.5\left(\mathrm{CHCH}_{3}\right), 19.1\left(\mathrm{CH}_{3}\right)$.

5.1.3.22. 1-(1H-Indol-2-yl)-2-pyridin-2-yl-ethanone (8a). Prepared from commercial $1 H$-indole-2-carboxylic acid ethyl ester 3a (218 mg, $1.12 \mathrm{mmol}$ ) and 2-picoline. Yellow solid $(237 \mathrm{mg}$, 90\%), mp $140-141^{\circ} \mathrm{C}$. LC-MS $R_{\mathrm{t}} 5.5$ min (method 1), $9.7 \mathrm{~min}$ (method 2); $\mathrm{m} / z\left[\mathrm{MH}^{+}\right] 237 .{ }^{1} \mathrm{H}$ NMR $\delta 11.75(1 \mathrm{H}$, br s, indole$\mathrm{H} 1), 8.45(1 \mathrm{H}, \mathrm{dd}, J=4.8,0.9 \mathrm{~Hz}, \mathrm{ArH}), 7.72(1 \mathrm{H}, \mathrm{dd}, J=7.6$, $1.8 \mathrm{~Hz}, \mathrm{ArH}), 7.67(1 \mathrm{H}, \mathrm{d}, J=8.0 \mathrm{~Hz}, \operatorname{ArH}), 7.44(1 \mathrm{H}, \mathrm{d}, J=1.6 \mathrm{~Hz}$, $\mathrm{ArH}), 7.42-7.38(2 \mathrm{H}$, overlapped, $2 \mathrm{ArH}), 7.26-7.21(2 \mathrm{H}$, overlapped, $2 \mathrm{ArH}), 7.04(1 \mathrm{H}, \mathrm{t}, J=7.7 \mathrm{~Hz}, \mathrm{ArH}), 4.43\left(2 \mathrm{H}, \mathrm{s}, \mathrm{CH}_{2}\right) .{ }^{13} \mathrm{C}$ NMR $\delta 190.0(\mathrm{C}=\mathrm{O}), 156.4$ (ArC), $149.7(\operatorname{ArC}), 138.4(\operatorname{ArC}), 137.2$ (ArC), 135.8 (ArC), 127.4 (ArC), 126.1 (ArC), 124.9 (ArC), 123.3 (ArC), 122.4 (ArC), 120.8 (ArC), 113.3 (ArC), 110.8 (ArC), 48.0 $\left(\mathrm{CH}_{2}\right)$. Anal. Calcd for $\mathrm{C}_{15} \mathrm{H}_{12} \mathrm{~N}_{2} \mathrm{O}$ : C, 76.25; $\mathrm{H}, 5.12 ; \mathrm{N}, 11.86$. Found: C, 76.09; H, 5.06; N, 11.74.

5.1.3.23. 1-(1H-Indol-2-yl)-2-pyridin-4-yl-ethanone (9a $)^{47}$. Prepared from commercial $1 \mathrm{H}$-indole-2-carboxylic acid ethyl ester 3a (220 mg, $1.13 \mathrm{mmol}$ ) and 4-picoline. Bright yellow solid (240 mg, 90\%), mp $169-170{ }^{\circ} \mathrm{C}$. LC-MS $R_{\mathrm{t}} 5.0 \mathrm{~min}$ (method 1 ), $8.1 \mathrm{~min}(\operatorname{method} 2) ; \mathrm{m} / z\left[\mathrm{MH}^{+}\right] 237 .{ }^{1} \mathrm{H}$ NMR $\delta 11.79(1 \mathrm{H}$, br s, indole-H1), $8.48(2 \mathrm{H}, \mathrm{d}, J=6.0 \mathrm{~Hz}, 2 \mathrm{ArH}), 7.68(1 \mathrm{H}, \mathrm{d}, J=8.0 \mathrm{~Hz}, \mathrm{ArH})$, $7.55(1 \mathrm{H}, \mathrm{d}, J=1.1 \mathrm{~Hz}, \mathrm{ArH}), 7.41(1 \mathrm{H}, \mathrm{dd}, J=8.3,0.8 \mathrm{~Hz}, \mathrm{ArH}), 7.34$ $(2 \mathrm{H}, \mathrm{d}, J=6.0 \mathrm{~Hz}, 2 \mathrm{ArH}), 7.26(1 \mathrm{H}, \mathrm{dt}, J=7.7,1.1 \mathrm{~Hz}, \operatorname{ArH}), 7.06(1 \mathrm{H}$, $\mathrm{dt}, J=7.5,0.8 \mathrm{~Hz}, \mathrm{ArH}), 4.35\left(2 \mathrm{H}, \mathrm{s}, \mathrm{CH}_{2}\right) .{ }^{13} \mathrm{C}$ NMR $\delta 189.5(\mathrm{C}=\mathrm{O})$, 150.0 (2 ArC), 144.8 ( $\operatorname{ArC}), 138.6(\operatorname{ArC}), 135.4(\operatorname{ArC}), 127.4(\operatorname{ArC})$, 126.3 (2 ArC), 125.6 (ArC), 123.3 (ArC), 120.9 (ArC), 113.3 (ArC), 110.9 (ArC), $44.2\left(\mathrm{CH}_{2}\right)$. Anal. Calcd for $\mathrm{C}_{15} \mathrm{H}_{12} \mathrm{~N}_{2} \mathrm{O}: \mathrm{C}, 76.25 ; \mathrm{H}$, 5.12; N, 11.86. Found: C, 75.68; H, 5.09; N, 11.73 .

5.1.3.24. 1-(1H-Indol-2-yl)-2-pyrazin-2-yl-ethanone (10a). Prepared from commercial $1 H$-indole-2-carboxylic acid ethyl ester 3a (195 mg, $1.00 \mathrm{mmol}$ ) and 2-methylpyrazine. Yellow solid (97 mg, 41\%), mp $175-176{ }^{\circ} \mathrm{C}$. LC-MS $R_{\mathrm{t}} 5.5 \mathrm{~min}$ (method 1 ), 11.0 min (method 2); $m / z\left[\mathrm{MH}^{+}\right] 238 .{ }^{1} \mathrm{H}$ NMR $\delta 11.80(1 \mathrm{H}$, br s, indole-H1), $8.69(1 \mathrm{H}, \mathrm{d}, J=1.6 \mathrm{~Hz}, \mathrm{ArH}), 8.56(1 \mathrm{H}, \mathrm{dd}, J=2.5,1.6 \mathrm{~Hz}$, $\operatorname{ArH}), 8.51(1 \mathrm{H}, \mathrm{d}, J=2.5 \mathrm{~Hz}, \operatorname{ArH}), 7.69(1 \mathrm{H}, \mathrm{d}, J=8.0 \mathrm{~Hz}, \operatorname{ArH})$, $7.51(1 \mathrm{H}, \mathrm{d}, J=1.6 \mathrm{~Hz}, \operatorname{ArH}), 7.41(1 \mathrm{H}, \mathrm{d}, J=8.3 \mathrm{~Hz}, \operatorname{ArH}), 7.26$ $(1 \mathrm{H}, \mathrm{dt}, J=7.7,0.9 \mathrm{~Hz}, \operatorname{ArH}), 7.06(1 \mathrm{H}, \mathrm{dt}, J=7.6,0.7 \mathrm{~Hz}, \mathrm{ArH})$, $4.57\left(2 \mathrm{H}, \mathrm{s}, \mathrm{CH}_{2}\right) .{ }^{13} \mathrm{C}$ NMR $\delta 189.3(\mathrm{C}=\mathrm{O}), 152.4(\mathrm{ArC}), 146.4$ (ArC), 144.7 (ArC), 143.4 (ArC), 138.5 (ArC), 135.5 (ArC), 127.4 (ArC), 126.3 (ArC), 123.3 (ArC), 120.9 (ArC), 113.3 (ArC), 110.9 (ArC), $45.1\left(\mathrm{CH}_{2}\right)$. Anal. Calcd for $\mathrm{C}_{14} \mathrm{H}_{11} \mathrm{~N}_{3} \mathrm{O}: \mathrm{C}, 70.87 ; \mathrm{H}, 4.67 ; \mathrm{N}$, 17.71. Found: C, 70.03; H, 4.63; N, 17.63 .

5.1.3.25. 1-(1H-Indol-2-yl)-2-phenylethanone $(11 a)^{36,48}$ and 2(1H-indol-2-yl)-1,3-diphenylpropan-2-ol (16). An oven-dried flask was purged with argon while hot, then allowed to cool down to room temperature under argon and charged with dry THF (1 mL) 
and benzyl magnesium chloride, $2.0 \mathrm{M}$ solution in THF ( $1 \mathrm{~mL}$, $2.0 \mathrm{mmol}$ ) to give a clear grayish-yellowish solution. The solution was cooled in an ice/water bath and a solution of $1 \mathrm{H}$-indole-2-carboxylic acid ethyl ester 3a (104 mg, $0.53 \mathrm{mmol})$ in dry THF ( $2 \mathrm{~mL}$ ) was added dropwise over the flask wall. Clear yellowish solution was allowed to attain room temperature overnight. After $22 \mathrm{~h}$ of total reaction time (the mixture turned greenish), the reaction was quenched with saturated aqueous ammonium chloride solution ( $5 \mathrm{~mL}$ ). Upon stirring for several minutes, the mixture was partitioned between ethyl acetate and water. The aqueous phase was extracted with ethyl acetate and the combined organic layers were washed with brine and dried over $\mathrm{MgSO}_{4}$. Chromatographic purification yielded the two products: 11a: eluted with $\sim 7 \%$ ethyl acetate. Yellowish solid ( $46 \mathrm{mg}, 37 \%$ ), mp $125-133^{\circ} \mathrm{C}$. LC-MS $R_{\mathrm{t}}$ $6.8 \mathrm{~min}(\operatorname{method} 1), 16.6 \mathrm{~min}(\operatorname{method} 2) ; \mathrm{m} / \mathrm{z}\left[\mathrm{MH}^{+}\right] 236 .{ }^{1} \mathrm{H}$ NMR $\delta 11.73(1 \mathrm{H}$, br s, indole-H1), $7.67(1 \mathrm{H}, \mathrm{d}, J=8.0 \mathrm{~Hz}, \operatorname{ArH})$, $7.53(1 \mathrm{H}, \mathrm{m}, \mathrm{ArH}), 7.40(1 \mathrm{H}, \mathrm{d}, J=8.2 \mathrm{~Hz}, \mathrm{ArH}), 7.33-7.20(6 \mathrm{H}$, overlapped, $6 \mathrm{ArH}), 7.05(1 \mathrm{H}, \mathrm{dt}, J=7.6,0.9 \mathrm{~Hz}, \mathrm{ArH}), 4.25\left(2 \mathrm{H}, \mathrm{s}, \mathrm{CH}_{2}\right)$. ${ }^{13} \mathrm{C}$ NMR $\delta 190.8(\mathrm{C}=\mathrm{O}), 138.5(\operatorname{ArC}), 136.0(\operatorname{ArC}), 135.6(\operatorname{ArC}), 130.0$ (2 ArC), 128.9 (2 ArC), 127.4 (ArC), 127.1 (ArC), 126.1 (ArC), 123.2 (ArC), $120.8(\mathrm{ArC}), 113.3(\mathrm{ArC}), 110.7(\mathrm{ArC}), 45.1\left(\mathrm{CH}_{2}\right)$. Anal. Calcd for $\mathrm{C}_{16} \mathrm{H}_{13} \mathrm{NO}$ : C, 81.68; H, 5.57; N, 5.95. Found: C, 80.67; H, 6.16; N, 5.51. 16: eluted with $\sim 9 \%$ ethyl acetate. White solid (30 $\mathrm{mg}, 17 \%$ ), mp $160-163^{\circ} \mathrm{C}$. LC-MS $R_{\mathrm{t}} 7.2 \mathrm{~min}$ (method 1 ), $19.0 \mathrm{~min}$ (method 2); $m / z\left[\mathrm{MH}^{+}\right]$328. ${ }^{1} \mathrm{H}$ NMR $\delta 10.75(1 \mathrm{H}$, br s, indole-H1), 7.31 $(1 \mathrm{H}, \mathrm{d}, J=7.8 \mathrm{~Hz}, \mathrm{ArH}), 7.27(1 \mathrm{H}, \mathrm{d}, J=8.0 \mathrm{~Hz}, \operatorname{ArH}), 7.09-7.03$ (6H, overlapped, $6 \mathrm{ArH}), 6.98-6.96(4 \mathrm{H}$, overlapped, $4 \mathrm{ArH}), 6.92$ $(1 \mathrm{H}, \mathrm{dt}, J=7.5,1.0 \mathrm{~Hz}, \mathrm{ArH}), 6.84(1 \mathrm{H}, \mathrm{dt}, J=7.3,0.9 \mathrm{~Hz}, \mathrm{ArH})$, $6.04(1 \mathrm{H}, \mathrm{d}, J=1.4 \mathrm{~Hz}, \mathrm{ArH}), 5.18(1 \mathrm{H}, \mathrm{s}, \mathrm{OH}), 3.17(2 \mathrm{H}, \mathrm{d}$, $\left.J_{\text {gem }}=13.5 \mathrm{~Hz}, \mathrm{CH}_{2}\right), 3.04\left(2 \mathrm{H}, \mathrm{d}, J_{\text {gem }}=13.5 \mathrm{~Hz}, \mathrm{CH}_{2}\right) .{ }^{13} \mathrm{C} \mathrm{NMR} \delta$ 144.7 (ArC), 138.1 (2C, $\operatorname{ArC}), 136.2$ (ArC), 131.0 (4C, ArC), 128.3 (ArC), 127.9 (4C, ArC), 126.3 (2C, ArC), 120.5 (ArC), 119.9 ( $\operatorname{ArC})$, 118.9 ( $\mathrm{ArC}), 111.6(\mathrm{ArC}), 98.9(\mathrm{ArC}), 75.0(\mathrm{COH}), 48.0\left(2 \mathrm{C}, \mathrm{CH}_{2}\right)$. Anal. Calcd for $\mathrm{C}_{23} \mathrm{H}_{21} \mathrm{NO}$ : C, 84.37; $\mathrm{H}, 6.46 ; \mathrm{N}, 4.28$. Found: C, 83.84; $\mathrm{H}, 6.82 ; \mathrm{N}, 3.91$.

5.1.3.26. 1-(1-Methyl-1H-indol-2-yl)-2-pyridin-3-yl-ethanone $(\mathbf{1 2 a})^{\mathbf{4 3}}$. Prepared from 1-methyl-1H-indole-2-carboxylic acid methyl ester 6a (method C; $544 \mathrm{mg}, 2.88 \mathrm{mmol}$ ) and 3-picoline. Bright yellow solid $(243 \mathrm{mg}, 34 \%)$, mp $75-77^{\circ} \mathrm{C}$. LC-MS $R_{\mathrm{t}}$ 5.9 min (method 1); $m / z\left[\mathrm{MH}^{+}\right]$251. ${ }^{1} \mathrm{H}$ NMR $\delta 8.51(1 \mathrm{H}, \mathrm{s}, \mathrm{ArH})$, $8.43(1 \mathrm{H}, \mathrm{d}, J=4.6 \mathrm{~Hz}, \mathrm{ArH}), 7.74-7.69(3 \mathrm{H}$, overlapped, 3 ArH), $7.55(1 \mathrm{H}, \mathrm{d}, J=8.5 \mathrm{~Hz}, \mathrm{ArH}), 7.37-7.31$ (2H, overlapped, 2 $\operatorname{ArH}), 7.13(1 \mathrm{H}, \mathrm{t}, J=7.5 \mathrm{~Hz}, \mathrm{ArH}), 4.39\left(2 \mathrm{H}, \mathrm{s}, \mathrm{CH}_{2}\right), 3.95(3 \mathrm{H}, \mathrm{s}$, $\left.\mathrm{CH}_{3}\right) .{ }^{13} \mathrm{C}$ NMR $\delta 191.2(\mathrm{C}=\mathrm{O}), 151.1(\mathrm{ArC}), 148.3(\mathrm{ArC}), 140.4$ (ArC), 137.8 (ArC), 134.5 (ArC), 131.7 (ArC), 126.5 (ArC), 125.9 $(\mathrm{ArC}), 123.9(\mathrm{ArC}), 123.4(\mathrm{ArC}), 121.3(\operatorname{ArC}), 113.0(\operatorname{ArC})$, 111.5 (ArC), $43.3\left(\mathrm{CH}_{2}\right), 32.5\left(\mathrm{CH}_{3}\right)$. Anal. Calcd for $\mathrm{C}_{16} \mathrm{H}_{14} \mathrm{~N}_{2} \mathrm{O}$ : C, 76.78; H, 5.64; N, 11.19. Found: C, 77.64; H, 5.68; N, 11.24 .

5.1.3.27. 1-(1H-Indol-2-yl)-2-pyridin-3-ylethanol $\quad(18)^{49}$. Ammonium formate $(845 \mathrm{mg}, 13.4 \mathrm{mmol}$ ) and Pd black (surface area $40-60 \mathrm{~m}^{2} / \mathrm{g}, 38 \mathrm{mg}, 0.36 \mathrm{mmol}$ ) were added to a stirred solution of ketone 7a (203 mg, $0.86 \mathrm{mmol})$ in dry methanol $(100 \mathrm{~mL})$. As no significant amount of alcohol 18 was detected by TLC after $24 \mathrm{~h}$, more Pd black (163 mg, $1.54 \mathrm{mmol}$ ) was added. Three days later, as TLC indicated complete consumption of starting material, the reaction mixture was filtered through Celite 545 and the filter was extensively washed with methanol. Concentration under reduced pressure, dilution with a small volume of ethyl acetate and precipitation with cyclohexane yielded the title product as an dark orange solid (183 mg, 89\%), mp $144-151{ }^{\circ} \mathrm{C}$ with decomposition. LC-MS $R_{\mathrm{t}} 4.4 \mathrm{~min}$ (method 1 ); $\mathrm{m} / z\left[\mathrm{MH}^{+}\right] 239 .{ }^{1} \mathrm{H}$ NMR $\delta$ $11.06(1 \mathrm{H}$, br s, indole-H1), 8.35-8.32 (2H, overlapped, $2 \mathrm{ArH})$, $7.56(1 \mathrm{H}, \mathrm{d}, J=7.8 \mathrm{~Hz}, \mathrm{ArH}), 7.39(1 \mathrm{H}, \mathrm{d}, J=7.8 \mathrm{~Hz}, \mathrm{ArH}), 7.30$ $(1 \mathrm{H}, \mathrm{d}, J=8.0 \mathrm{~Hz}, \mathrm{ArH}), 7.23(1 \mathrm{H}, \mathrm{dd}, J=7.8,4.8 \mathrm{~Hz}, \mathrm{ArH}), 6.98$
$(1 \mathrm{H}, \mathrm{t}, J=7.4 \mathrm{~Hz}, \mathrm{ArH}), 6.89(1 \mathrm{H}, \mathrm{t}, J=7.4 \mathrm{~Hz}, \operatorname{ArH}), 6.18(1 \mathrm{H}, \mathrm{br} \mathrm{s}$, ArH $), 5.59(1 \mathrm{H}$, br s, OH $), 4.88(1 \mathrm{H}, \mathrm{m}, \mathrm{CHOH}), 3.10(1 \mathrm{H}, \mathrm{dd}$, $\left.{ }^{2} J_{\mathrm{HH}}=13.7 \mathrm{~Hz},{ }^{3} J_{\mathrm{HH}}=5.5 \mathrm{~Hz}, \mathrm{CH}_{2}\right), 3.01\left(1 \mathrm{H}, \mathrm{dd},{ }^{2} J_{\mathrm{HH}}=13.7 \mathrm{~Hz}\right.$, $\left.{ }^{3} J_{\mathrm{HH}}=7.9 \mathrm{~Hz}, \mathrm{CH}_{2}\right) .{ }^{13} \mathrm{C}$ NMR $\delta 151.0(\operatorname{ArC}), 147.7(\mathrm{ArC}), 143.1$ (ArC), 137.3 (ArC), 136.5 (ArC), 134.8 (ArC), 128.2 (ArC), 123.7 (ArC), 121.0 (ArC), 120.2 (ArC), 119.2 (ArC), 111.7 (ArC), 98.4 ( $\operatorname{ArC}), 74.3(\mathrm{CHOH}), 41.0\left(\mathrm{CH}_{2}\right)$.

5.1.3.28. 2-(2-Pyridin-3-ylethyl)-1H-indole $\quad(\mathbf{1 9})^{50}$. Prepared according to a literature procedure. ${ }^{51}$ A suspension of indole ketone $7 \mathrm{a}(111 \mathrm{mg}, 0.47 \mathrm{mmol})$, hydrazine hydrate $(47 \mu \mathrm{l}$, $0.97 \mathrm{mmol}$ ) and potassium hydroxide pellets (130 $\mathrm{mg}, 2.32 \mathrm{mmol})$ in ethylene glycol $(5 \mathrm{~mL})$ was subjected to microwave heating at $195^{\circ} \mathrm{C}$ for $1 \mathrm{~h}(P \sim 40 \mathrm{~W}, p=1-3 \mathrm{bar})$. The resulting clear dark orange solution was partitioned between dichloromethane and saturated aqueous ammonium chloride. The aqueous phase was extracted twice with dichloromethane and the combined organic layers were dried over $\mathrm{MgSO}_{4}$. Concentration of the filtered solution combined with the addition of cyclohexane yielded the title product as an ochre solid ( $87 \mathrm{mg}, 84 \%$ ), $\mathrm{mp} 139-142{ }^{\circ} \mathrm{C}$. LC-MS $R_{\mathrm{t}}$ $5.2 \min (\operatorname{method} 1) ; m / z\left[\mathrm{MH}^{+}\right] 223 .{ }^{1} \mathrm{H}$ NMR $\delta 10.95(1 \mathrm{H}$, br s, indole-H1), $8.41(1 \mathrm{H}, \mathrm{s}, \mathrm{ArH}), 8.35(1 \mathrm{H}, \mathrm{d}, J=4.8 \mathrm{~Hz}, \mathrm{ArH}), 7.61(1 \mathrm{H}$, dd, $J=7.8,1.6 \mathrm{~Hz}, \mathrm{ArH}), 7.35(1 \mathrm{H}, \mathrm{d}, J=7.8 \mathrm{~Hz}, \mathrm{ArH}), 7.27-7.24$ (2H, overlapped, $2 \mathrm{ArH}), 6.95(1 \mathrm{H}, \mathrm{t}, J=7.5 \mathrm{~Hz}, \operatorname{ArH}), 6.88(1 \mathrm{H}, \mathrm{t}$ $J=7.5 \mathrm{~Hz}, \operatorname{ArH}), 6.09(1 \mathrm{H}, \mathrm{s}, \mathrm{ArH}), 3.00\left(4 \mathrm{H}\right.$, overlapped, $\left.2 \mathrm{CH}_{2}\right)$. ${ }^{13} \mathrm{C}$ NMR $\delta 150.1$ (ArC), 147.8 (ArC), $139.4(\operatorname{ArC}), 137.2(\operatorname{ArC})$, 136.5 (ArC), 136.3 (ArC), 128.8 (ArC), $123.9(\operatorname{ArC}), 120.7$ (ArC), 119.7 (ArC), 119.1 (ArC), 111.2 (ArC), 99.2 (ArC), $32.2\left(\mathrm{CH}_{2}\right), 29.6$ $\left(\mathrm{CH}_{2}\right)$. Anal. Calcd for $\mathrm{C}_{15} \mathrm{H}_{14} \mathrm{~N}_{2}$ : C, 81.05; $\mathrm{H}, 6.35 ; \mathrm{N}, 12.60$. Found: C, 80.33; H, 6.13; N, 12.15.

5.1.3.29. 1-(1H -Indol-2-yl)-2-(pyridin-3-yl)ethanone oxime (20). A suspension of ketone $7 \mathbf{a}(52 \mathrm{mg}, 0.22 \mathrm{mmol})$, hydroxylamine hydrochloride $(17 \mathrm{mg}, 0.24 \mathrm{mmol})$ and pyridine $(20 \mu \mathrm{l}$, $0.25 \mathrm{mmol})$ in absolute ethanol $(1 \mathrm{~mL})$ was subjected to microwave heating at $120^{\circ} \mathrm{C}$ for $30 \mathrm{~min}$. The resulting clear yellow solution was evaporated with silica and oxime $\mathbf{2 0}$ was purified by automated flash chromatography to yield a white solid (13 mg, 24\%), mp $187-192{ }^{\circ} \mathrm{C}$. LC-MS $R_{\mathrm{t}} 5.2 \min (\operatorname{method} 1) ; \mathrm{m} / z\left[\mathrm{MH}^{+}\right] 252 .{ }^{1} \mathrm{H}$ NMR $\delta 11.43(1 \mathrm{H}$, br s), $11.11(1 \mathrm{H}$, br s $), 8.55(1 \mathrm{H}, \mathrm{d}, J=1.8 \mathrm{~Hz}, \mathrm{ArH})$, $8.34(1 \mathrm{H}, \mathrm{dd}, J=4.8,1.6 \mathrm{~Hz}, \operatorname{ArH}), 7.65(1 \mathrm{H}, \mathrm{d}, J=7.8 \mathrm{~Hz}, \operatorname{ArH}), 7.47$ $(1 \mathrm{H}, \mathrm{d}, J=8.0 \mathrm{~Hz}, \operatorname{ArH}), 7.34(1 \mathrm{H}, \mathrm{d}, J=8.2 \mathrm{~Hz}, \operatorname{ArH}), 7.26(1 \mathrm{H}, \mathrm{dd}$, $J=7.9,4.8 \mathrm{~Hz}, \operatorname{ArH}), 7.07(1 \mathrm{H}, \mathrm{t}, J=7.6 \mathrm{~Hz}, \operatorname{ArH}), 6.93(1 \mathrm{H}, \mathrm{t}$, $J=7.6 \mathrm{~Hz}, \mathrm{ArH}), 6.84(1 \mathrm{H}, \mathrm{d}, J=2.1 \mathrm{~Hz}, \mathrm{ArH}), 4.08\left(2 \mathrm{H}, \mathrm{s}, \mathrm{CH}_{2}\right) \cdot{ }^{13} \mathrm{C}$ NMR $\delta 150.3$ (C), 149.5 (C), 147.9 (C), 137.7 (ArC), 136.5 (ArC), 134.2 (ArC), 134.0 (ArC), 128.1 (ArC), 124.1 (ArC), 123.2 (ArC), $120.9(\mathrm{ArC}), 119.7(\mathrm{ArC}), 112.2(\mathrm{ArC}), 103.7(\mathrm{ArC}), 28.8\left(\mathrm{CH}_{2}\right){ }^{44}$

5.1.3.30. $1 H$-Indole-2-carboxylic acid pyridin-3-ylamide (21). A yellow suspension of $1 \mathrm{H}$-indole-2-carboxylic acid $(482 \mathrm{mg}$, $2.95 \mathrm{mmol}$ ) in thionyl chloride $(5 \mathrm{~mL})$ was boiled for $15 \mathrm{~min}$, during which time the mixture became a clear dark brown solution. This was concentrated under reduced pressure and the solid residue was evaporated three times with toluene. 3-Aminopyridine (306 mg, $3.22 \mathrm{mmol}$ ) and diisopropylethylamine (785 $\mu \mathrm{l}$, $4.43 \mathrm{mmol}$ ) were dissolved in dry THF $(2 \mathrm{~mL})$ to give a clear yellowish solution which was cooled to $0^{\circ} \mathrm{C}$. A solution of the above $1 \mathrm{H}$ indole-2-carbonyl chloride residue in THF $(3 \mathrm{~mL}$ ) was added carefully to give a red-brown mixture. The ice/water bath was removed after $5 \mathrm{~min}$ and the reaction mixture was stirred for a further $25 \mathrm{~min}$ and then partitioned between ethyl acetate and water. The aqueous layer is extracted twice with ethyl acetate and the combined organic layers were washed with brine and dried over $\mathrm{MgSO}_{4}$. Chromatographic purification (the title product eluted with $50-60 \%$ ethyl acetate) afforded amide $\mathbf{2 1}$ as a yellow solid (372 mg, $53 \%$ ), decomposes without melting above $258^{\circ} \mathrm{C}$. LC-MS $R_{\mathrm{t}} 5.1 \mathrm{~min}$ 
(method 1); $m / z\left[\mathrm{MH}^{+}\right] 238 .{ }^{1} \mathrm{H}$ NMR $\delta 11.80(1 \mathrm{H}$, br s, indole-H1), $10.40(1 \mathrm{H}, \mathrm{s}, \mathrm{CONH}), 8.95(1 \mathrm{H}, \mathrm{d}, J=2.3 \mathrm{~Hz}, \operatorname{ArH}), 8.29(1 \mathrm{H}, \mathrm{dd}$, $J=4.6,1.2 \mathrm{~Hz}, \operatorname{ArH}), 8.19(1 \mathrm{H}, \mathrm{dd}, J=8.4,1.6 \mathrm{~Hz}, \operatorname{ArH}), 7.66(1 \mathrm{H}, \mathrm{d}$, $J=8.0 \mathrm{~Hz}, \mathrm{ArH}), 7.45-7.42(2 \mathrm{H}$, overlapped, $2 \mathrm{ArH}), 7.38(1 \mathrm{H}$, dd, $J=8.3,4.8 \mathrm{~Hz}, \operatorname{ArH}), 7.21(1 \mathrm{H}, \mathrm{t}, J=7.5 \mathrm{~Hz}, \operatorname{ArH}), 7.05(1 \mathrm{H}, \mathrm{t}$, $J=7.5 \mathrm{~Hz}, \mathrm{ArH}) .{ }^{13} \mathrm{C}$ NMR $\delta 160.6(\mathrm{CONH}), 145.0$ (ArC), 142.2 (ArC), 137.5 (ArC), 136.2 (ArC), 131.5 (ArC), 127.6 (ArC), 127.5 $(\mathrm{ArC}), 124.6$ (ArC), $124.2(\mathrm{ArC}), 122.4$ (ArC), 120.6 (ArC), 113.0 (ArC), 104.9 (ArC). Anal. Calcd for $\mathrm{C}_{14} \mathrm{H}_{11} \mathrm{~N}_{3} \mathrm{O}: \mathrm{C}, 70.87 ; \mathrm{H}$, 4.67; N, 17.71. Found: C, 70.66; H, 4.57; N, 17.76.

\subsection{Biology}

\subsubsection{Protein expression and purification of recombinant human IDO}

The coding region for human IDO (Ala2-Gly403) was cloned into a derivative of plasmid pET9 (Novagen). The recombinant plasmid, pETIDO, encodes a histidine tag at the N-terminus of IDO. Bacterial strain BL21 AI (Invitrogen) was used for overexpression of IDO and transformed with the pETIDO plasmid. The transformed cells were grown on a rotary shaker at $37^{\circ} \mathrm{C}$ and $220 \mathrm{rpm}$ to an OD600 of 1.2 in LB medium supplemented with $25 \mu \mathrm{g} / \mathrm{mL}$ kanamycin, $50 \mu \mathrm{g} / \mathrm{mL}$ L-tryptophan and $10 \mu \mathrm{M}$ bovine hemin (Sigma). The culture was cooled in a water/ice bath and supplemented again with $50 \mu \mathrm{g} /$ $\mathrm{mL}$ L-tryptophan and $10 \mu \mathrm{M}$ bovine hemin. The expression of Histagged IDO was induced by the addition of $1 \%(\mathrm{w} / \mathrm{v})$ arabinose. Induced cells were grown at $20^{\circ} \mathrm{C}$ and $60 \mathrm{rpm}$ for $20 \mathrm{~h}$. Cells $(1 \mathrm{~L}$ culture) were collected by centrifugation, resuspended in $40 \mathrm{~mL}$ of $25 \mathrm{mM}$ Mes, $150 \mathrm{mM} \mathrm{KCl}, 10 \mathrm{mM}$ imidazole, and protease inhibitors (complete EDTA free, Roche Applied Science) (pH 6.5), and disrupted with a French press. The extract was clarified by centrifugation and filtration on a $0.22 \mu \mathrm{m}$ filter. The enzyme was purified by IMAC using Ni2p as a ligand and an IMAC HITRAP column $(5 \mathrm{~mL}$, GE Healthcare). Briefly, the extract was loaded on the column with $25 \mathrm{mM}$ Mes, $150 \mathrm{mM} \mathrm{KCl}$, and $10 \mathrm{mM}$ imidazole ( $\mathrm{pH}$ 6.5). The column was washed with $50 \mathrm{~mL}$ of the same buffer with the imidazole concentration adjusted to $100 \mathrm{mM}$. Finally, the protein was eluted with $25 \mathrm{mM}$ Mes, $150 \mathrm{mM} \mathrm{KCl}$, and $50 \mathrm{mM}$ EDTA (pH 6.5). The buffer was then exchanged into $25 \mathrm{mM}$ Mes and $150 \mathrm{mM} \mathrm{KCl}$ (pH 6.5) using a HITRAP desalting column (GE Healthcare). The purity of the enzyme was estimated to be $>95 \%$ based on the SDS-PAGE gel and Coomassie blue staining. The ratio of absorbance at $404 \mathrm{~nm}$ to that at $280 \mathrm{~nm}$ of the protein was around 1.9 .

\subsubsection{Assay buffer}

Assay buffer was composed of Phosphate Buffer $50 \mathrm{mM}$ (pH 6.5), Methylene Blue $5 \mu \mathrm{M}$ (Sigma-Aldrich, M9140), and Ascorbic Acid $40 \mathrm{mM}$ (Sigma-Aldrich, A5960). L-Tryptophan substrate (Sigma-Aldrich, T0254) is diluted at $100 \mu \mathrm{M}$ in Assay Buffer. IDO enzyme was diluted in Phosphate Buffer $50 \mathrm{mM}$ at $0.05 \mathrm{mg} / \mathrm{ml}$ Hydrogen peroxide solution (Sigma-Aldrich, H1009) is prepared at a concentration of $10 \mathrm{mM}$ in water.

\subsubsection{Enzymatic assay}

Enzymatic Assay was performed in 384 Wells microplates (Greiner bio one, 781108). Ninety five microliters of reaction buffer with L-Tryptophan substrate at $100 \mu \mathrm{M}$ and compound to be tested are added in the microplate. The optical density at $320 \mathrm{~nm}$ of this mixture is first recorded as a baseline with a Spectramax plus spectrophotometer (Molecular Devices). The hIDO enzyme $(0.375 \mu \mathrm{g}$ in $5 \mu \mathrm{l}$ ) is then added to the mixture. After $60 \mathrm{~min}$ incubation at room temperature, the reaction is stopped by the addition of hydrogen peroxide $(1 \mathrm{mM})$ and a second optical reading at $320 \mathrm{~nm}$ is performed. The difference between the two density values reflects the level of tryptophan degradation and is used to calculate the percentage of IDO inhibition relative to the reference inhibitor
1-MT. Dose-response inhibition of IDO is analyzed using GraphPad Prism 4 program (GraphPad Software Inc.).

\subsection{Cellular tests}

\subsubsection{Cell line}

A plasmid construct encoding murine IDO was transfected into mouse mastocytoma line P815B. Clone P185B-mIDO clone 6 (Uyttenhove et al, 2003), which overexpresses IDO, was selected and used for the cellular assay. Mouse IDO shares a $62 \%$ sequence identity with human IDO, and the active site residues are $100 \%$ conserved.

\subsubsection{Assay}

The assay was performed in 96 -well flat bottom plates seeded with $2 \times 10^{5}$ cells in a final volume of $200 \mu$ l. To determine whether compounds were significant IDO, the cells were incubated overnight at $37^{\circ} \mathrm{C}$ in HBSS (Hanks Balanced Salt Solution, Invitrogen) supplemented with $80 \mu \mathrm{M}$ L-Tryptophan and $20 \mu \mathrm{M}$ of the compound. The plates were then centrifuged $10 \mathrm{~min}$ at $300 \mathrm{~g}$, and $150 \mu \mathrm{l}$ of the supernatant were collected. The supernatant was analyzed by HPLC to measure the concentration of tryptophan and kynurenine, based on the retention time and the UV absorption ( $280 \mathrm{~nm}$ for tryptophan, $360 \mathrm{~nm}$ for kynurenine). For the HPLC analysis, $50 \mu \mathrm{l}$ of supernatant were mixed with $500 \mu$ l acetonitrile to precipitate the proteins. After centrifugation, the supernatant was collected, concentrated on a speedvac, resuspended in a final volume of $100 \mu \mathrm{l}$ water and injected in the HPLC (C18 column). In those conditions, about $50 \%$ of the initial amount of tryptophan was degraded in the absence of inhibitor, and an equimolar amount of kynurenine was produced. The percentages of inhibition of tryptophan degradation and kynurenine production by the compounds were calculated in reference to this maximal activity. The initial wells containing the cells in the remaining volume of $50 \mu \mathrm{l}$ were used to estimate cell viability in a classical MTT assay. To that end, $50 \mu \mathrm{l}$ of culture medium (Iscove medium with $10 \%$ FCS and amino acids) were added to the wells together with $50 \mu \mathrm{l}$ of MTT. After $3-4 \mathrm{~h}$ of incubation at $37^{\circ} \mathrm{C}, 100 \mu \mathrm{l}$ of SDS/DMF were added to dissolve the crystals of formazan blue and the absorbance at $570 / 650 \mathrm{~nm}$ was measured after overnight incubation at $37^{\circ} \mathrm{C}$.

\subsection{X-ray determination}

X-ray measurements were performed on a Gemini Ultra R system (4-circle kappa platform, Ruby CCD detector) using MoKa radiation $(\lambda=0.71073 \AA$ ) for the two compounds. After mounting and centering of the single crystals on the diffractometer, cell parameters were estimated from a pre-experiment run and full datasets collected at room temperature. Software for data reduction was CrysAliPro. ${ }^{52}$ Structures were solved by direct methods from SHELXs-97 program ${ }^{53}$ and then refined on $F^{2}$ using SHELXL-97 software. Non-hydrogen atoms were anisotropically refined and the hydrogen atoms in the riding mode with isotropic temperature factors fixed at 1.2 times $U$ (equiv) of the parent atoms.

CCDC 794450 and 794451 contain the supplementary crystallographic data for this paper and can be obtained free of charge via www.ccdc.cam.ac.uk/conts/retrieving.html (or from the Cambridge Crystallographic Data Centre, 12, Union Road, Cambridge CB2 1EZ, UK; fax: +44 1223 336033; or deposit@ccdc.cam.ac.uk).

\subsection{Molecular modeling}

Molecular modeling studies were carried out on a Linux workstation. The compounds were built using the SKETCH module implemented in SYBYL (version 8.0). ${ }^{54}$ Docking was performed using the 3D-coordinates of TDO ( $\mathrm{pdb}$ code 2D0T) with the help of the 
automated GoLD program ${ }^{35}$ (active site definition: residues within $7 \AA$ around PIM). In order to take protein flexibility into account, the enzyme-inhibitor complexes were optimized using the minimize module. The minimization process uses the Powell method with the Tripos force field (dielectric constant $1 r$ ) to reach a final convergence of $0.01 \mathrm{kcal} \mathrm{mol}^{-1}$.

\section{Acknowledgments}

This work is supported by the FNRS (Belgium) and Biowin (CANTOL: convention $n^{\circ} 5678$ ). R.F. is greatly indebted to the Belgian 'Fonds de la Recherche Scientifique-FNRS' for the award of a postdoctoral research grant.

\section{Supplementary data}

Supplementary data associated with this article can be found, in the online version, at doi:10.1016/j.bmc.2010.12.032.

\section{References and notes}

1. Munn, D. H.; Mellor, A. L. J. Clin. Invest. 2007, 117, 1147.

2. Prendergast, G. C. Oncogene 2008, 27, 3889.

3. Rafice, S. A.; Chauhan, N.; Efimov, I.; Basran, J.; Raven, E. L. Biochem. Soc. Trans. 2009, 37, 408.

4. Sono, M.; Cady, S. G. Biochemistry 1989, 28, 5392.

5. Shimizu, T.; Nomiyama, S.; Hirata, F.; Hayaishi, O. J. Biol. Chem. 1978, 253, 4700.

6. Maghzal, G. J.; Thomas, S. R.; Hunt, N. H.; Stocker, R. J. Biol. Chem. 2008, 283, 12014.

7. Vottero, E.; Mitchell, D. A.; Page, M. J.; MacGillivray, R. T.; Sadowski, I. J.; Roberge, M.; Mauk, A. G. FEBS Lett. 2006, 580, 2265.

8. Hwu, P.; Du, M. X.; Lapointe, R.; Do, M.; Taylor, M. W.; Young, H. A. J. Immunol. 2000, 164, 3596.

9. Dantzer, R.; O'Connor, J. C.; Freund, G. G.; Johnson, R. W.; Kelley, K. W. Nat. Rev. Neurosci. 2008, 9, 46.

10. Schwarcz, R. Curr. Opin. Pharmacol. 2004, 4, 12.

11. Stone, T. W.; Darlington, L. G. Nat. Rev. Drug Discov. 2002, 1, 609.

12. Uyttenhove, C.; Pilotte, L.; Theate, I.; Stroobant, V.; Colau, D.; Parmentier, N.; Boon, T.; Van den Eynde, B. J. Nat. Med. 2003, 9, 1269.

13. Muller, A. J.; DuHadaway, J. B.; Donover, P. S.; Sutanto-Ward, E.; Prendergast, G. C. Nat. Med. 2005, 11, 312.

14. Okamoto, A.; Nikaido, T. Ochiai, K. Takakura, S. Saito, M. Aoki, Y: Ishii, N. Yanaihara, N.; Yamada, K.; Takikawa, O.; Kawaguchi, R.; Isonishi, S.; Tanaka, T.; Urashima, M. Clin. Cancer Res. 2005, 11, 6030.

15. Muller, A. J.; Malachowski, W. P.; Prendergast, G. C. Expert Opin. Ther. Targets 2005, 9, 831.

16. Muller, A. J.; Prendergast, G. C. Cancer Res. 2005, 65, 8065.

17. Muller, A. J.; Prendergast, G. C. Curr. Cancer Drug Targets 2007, 7, 31.

18. Macchiarulo, A.; Camaioni, E.; Nuti, R.; Pellicciari, R. Amino Acids 2009, 37, 219.

19. Cady, S. G.; Sono, M. Arch. Biochem. Biophys. 1991, 291, 326.

20. Eguchi, N.; Watanabe, Y.; Kawanishi, K.; Hashimoto, Y.; Hayaishi, O. Arch. Biochem. Biophys. 1984, 232, 602.

21. Banerjee, T.; Duhadaway, J. B.; Gaspari, P.; Sutanto-Ward, E.; Munn, D. H.; Mellor, A. L.; Malachowski, W. P.; Prendergast, G. C.; Muller, A. J. Oncogene 2008, 27, 2851
22. Gaspari, P.; Banerjee, T.; Malachowski, W. P.; Muller, A. J.; Prendergast G. C.; DuHadaway, J.; Bennett, S.; Donovan, A. M. J. Med. Chem. 2006, 49, 684.

23. Brastianos, H. C.; Vottero, E.; Patrick, B. O.; Van Soest, R.; Matainaho, T.; Mauk, A. G.; Andersen, R. J. J. Am. Chem. Soc. 2006, 128, 16046.

24. Pereira, A.; Vottero, E.; Roberge, M.; Mauk, A. G.; Andersen, R. J. J. Nat. Prod. 2006, 69, 1496

25. Sugimoto, H.; Oda, S.; Otsuki, T.; Hino, T.; Yoshida, T.; Shiro, Y. Proc. Natl. Acad Sci. U.S.A. 2006, 103, 2611.

26. Kumar, S.; Jaller, D.; Patel, B.; LaLonde, J. M.; DuHadaway, J. B.; Malachowski W. P.; Prendergast, G. C.; Muller, A. J. J. Med. Chem. 2008, 51, 4968.

27. Nakashima, $\mathrm{H}$; Uto, $\mathrm{Y}$; Nakata, E.; Nagasawa, H.; Ikkyu, K.; Hiraoka, N. Nakashima, K.; Sasaki, Y.; Sugimoto, H.; Shiro, Y.; Hashimoto, T.; Okamoto, Y.; Asakawa, Y.; Hori, H. Bioorg. Med. Chem. 2008, 16, 8661.

28. Carr, G.; Chung, M. K.; Mauk, A. G.; Andersen, R. J. J. Med. Chem. 2008, 51, 2634

29. Yue, E. W.; Douty, B.; Wayland, B.; Bower, M.; Liu, X.; Leffet, L.; Wang, Q. Bowman, K. J.; Hansbury, M. J.; Liu, C.; Wei, M.; Li, Y.; Wynn, R.; Burn, T. C.; Koblish, H. K.; Fridman, J. S.; Metcalf, B.; Scherle, P. A.; Combs, A. P. J. Med. Chem. 2009, 52, 7364.

30. Terentis, A. C.; Freewan, M.; Sempertegui Plaza, T. S.; Raftery, M. J.; Stocker, R.; Thomas, S. R. Biochemistry 2010, 49, 591.

31. Matsuno, K.; Takai, K.; Isaka, Y.; Unno, Y.; Sato, M.; Takikawa, O.; Asai, A. Bioorg. Med. Chem. Lett. 2010, 20, 5126.

32. Rohrig, U. F.; Awad, L.; Grosdidier, A.; Larrieu, P.; Stroobant, V.; Colau, D.; Cerundolo, V.; Simpson, A. J.; Vogel, P.; Van den Eynde, B. J.; Zoete, V.; Michielin, O. J. Med. Chem. 2010, 53, 1172.

33. Katz, J. B.; Muller, A. J.; Prendergast, G. C. Immunol. Rev. 2008, 222, 206.

34. Carr, R. A.; Congreve, M.; Murray, C. W.; Rees, D. C. Drug Discovery Today 2005 $10,987$.

35. Jones, G.; Willett, P.; Glen, R. C.; Leach, A. R.; Taylor, R. J. Mol. Biol. 1997, 267, 727.

36. Giorgioni, G.; Accorroni, B.; Di Stefano, A.; Marucci, G.; Siniscalchi, A.; Claudi, F. Med. Chem. Res. 2005, 14, 57.

37. Posner, G. H.; Whitten, C. E.; McFarland, P. E. J. Am. Chem. Soc. 1972, 94, 5106

38. Sato, T.; Naruse, K.; Enokiya, M.; Fujisawa, T. Chem. Lett. 1981, 1135.

39. Shinoda, P.; Tadokoro, M.; Tsukube, H.; Arakawa, R. Chem. Commun. 1998, 181

40. Colucci, M. C.; Reigan, P.; Siegel, D.; Chilloux, A.; Ross, D.; Moody, C. J. J. Med. Chem. 2007, 50, 5780 .

41. Lehmann, F.; Holm, M.; Laufer, S. Tetrahedron Lett. 2009, 50, 1708.

42. Capkova, K.; Yoneda, Y.; Dickerson, T. J.; Janda, K. D. Bioorg. Med. Chem. Lett. 2007, 17, 6463.

43. Sundberg, R. G.; Luis, J. G.; Parton, R. L.; Schreiber, S.; Srinivasan, P. C.; Lamb, P.; Forcier, P.; Bryan, R. B. J. Org. Chem. 1978, 23, 4859.

44. Lavilla, R.; Gotsen, T.; Gavalda, J.; Josep, M.; Santano, M. C.; Bosch, J. J. Chem Res., Synop. 1996, 8, 380.

45. Troin, Y.; Diez, A.; Bettiol, J.-L.; Rubiralta, M.; David, S.; Husson, H.-P. Heterocycles 1991, 32, 663.

46. Prieto, M.; Zurita, E.; Rosa, E.; Muñoz, L.; Lloyd-Williams, P.; Giralt, E. J. Org. Chem. 2004, 69, 6812.

47. Sundberg, R. J.; Smith, F. X. J. Org. Chem. 1975, 40, 2613.

48. Facoetti, D.; Abbiati, G.; Rossi, E. Eur. J. Org. Chem. 2009, 2872.

49. Salas, M.; Joule, J. A. J. Chem. Res., Synop. 1990, 3, 98.

50. Mohan, B.; Nagarathnam, D.; Vedachalam, M.; Srinivasan, P. C. Synthesis 1985 2, 188

51. Mahboobi, S.; Uecker, A.; Sellmer, A.; Cenac, C.; Hocher, H.; Pongratz, H.; Eichhorn, E.; Hufsky, H.; Trumpler, A.; Sicker, M.; Heidel, F.; Fischer T.; Stocking, C.; Elz, S.; Bohmer, F. D.; Dove, S. J. Med. Chem. 2006, 49, 3101.

52. CrysAlisPro. Oxford Diffraction Ltd.

53. Sheldrick, G. M. Acta Crystallogr., Sect. A 2008, 64, 112.

54. SYвYL 8.0, Tripos Inc. 1699 South Hanley Rd., St. Louis, Missouri 63144, USA 